\title{
Observations of Particle Size and Phase in Tropical Cyclones: Implications for Mesoscale Modeling of Microphysical Processes
}

\author{
Greg M. McFARQuHAR \\ Department of Atmospheric Sciences, University of Illinois at Urbana-Champaign, Urbana, Illinois \\ Robert A. BLACK \\ NOAA/AOML/HRD, Miami, Florida
}

(Manuscript received 27 August 2002, in final form 27 August 2003)

\begin{abstract}
Mesoscale model simulations of tropical cyclones are sensitive to representations of microphysical processes, such as fall velocities of frozen hydrometeors. The majority of microphysical parameterizations are based on observations obtained in clouds not associated with tropical cyclones, and hence their suitability for use in simulations of tropical cyclones is not known. Here, representations of mass-weighted fall speed $V_{m}$ for snow and graupel are examined to show that parameters describing the exponential size distributions and fall speeds of individual hydrometeors [through use of relations such as $V(D)=a D^{b}$ ] are identically important for determining $V_{m}$. The $a$ and $b$ coefficients are determined by the composition and shape of snow and graupel particles; past modeling studies have not adequately considered the possible spread of $a$ and $b$ values. Step variations in these coefficients, associated with different fall velocity regimes, however, do not have a large impact on $V_{m}$ for observed size distributions in tropical cyclones and the values of $a$ and $b$ used here, provided that coefficients are chosen in accordance with the sizes where the majority of mass occurs. New parameterizations for $V_{m}$ are developed such that there are no inconsistencies between the diameters used to define the mass, number concentration, and fall speeds of individual hydrometeors. Effects due to previous inconsistencies in defined diameters on mass conversion rates between different hydrometeor classes (e.g., snow, graupel, cloud ice) are shown to be significant.

In situ microphysical data obtained in Hurricane Norbert (1984) and Hurricane Emily (1987) with twodimensional cloud and precipitation probes are examined to determine typical size distributions of snow and graupel particles near the melting layer. Although well represented by exponential functions, there are substantial differences in how the intercept and slope of these distributions vary with mass content when compared to observations obtained in other locations; most notably, the intercepts of the size distributions associated with tropical cyclones increase with mass content, whereas some observations outside tropical cyclones show a decrease. Differences in the characteristics of the size distributions in updraft and downdraft regions, when compared to stratiform regions, exist, especially for graupel. A new representation for size distributions associated with tropical cyclones is derived and has significant impacts on the calculation of $V_{m}$.
\end{abstract}

\section{Introduction}

Model representations of the lifetime of clouds and of the production and evolution of precipitation are sensitive to the rate at which populations of solid phase hydrometeors fall. Using a single column model, Petch et al. (1997) showed that relatively small variations in ice crystal velocities could produce large differences in cloud mass and radiative properties. For the European Centre for Medium-Range Weather Forecasts (ECMWF) weather model, Klein and Jakob (1999) found that gravitational settling was the most important

Corresponding author address: Prof. Greg M. McFarquhar, Dept. of Atmospheric Sciences, University of Illinios at Urbana-Champaign, 105 S. Gregory Street, Urbana, IL 61801.

E-mail: mcfarq@atmos.uiuc.edu process controlling the abundance of ice in the high clouds of midlatitude cyclones, underscoring the need for careful evaluation of parameterizations of solid phase microphysics. By comparing different cirrus models for an idealized case, Starr et al. (2000) also noted that the ice water fallout process has a dominant effect on the vertical distribution of ice water and on the intensity of circulation within cirrus clouds.

Microphysical processes also feed back on the dynamics of tropical cyclones. Willoughby et al. (1984) showed that hurricane simulations with parameterized ice microphysics had a very different structure and evolution compared to those with liquid water microphysics. They, together with Lord et al. (1984) and Lord and Lord (1988), showed that the extent and intensity of mesoscale downdrafts associated with latent heat release 
are determined by the horizontal advection of hydrometeors from the convection, together with the fall speeds of snow and graupel and the conversion rates between hydrometeor species. These downdrafts contribute to the formation of multiple convective rings, which in turn modifies storm development (Willoughby et al. 1984).

This study aims to acquire a better understanding of how the size, density, and shape of solid hydrometeors affects the fallout of snow and graupel in tropical cyclones, and to develop better representations of such processes for numerical models. This study is timely for a number of reasons. First, the majority of current microphysical schemes are based on microphysical observations obtained in midlatitudes (e.g., Gunn and Marshall 1958; Sekhon and Srivastava 1970), and it is not known whether these observations are representative of tropical cyclones. McCumber et al. (1991) showed that model simulations are sensitive not only to the choice of parameterization scheme but also to details of assumed particle size distributions and hydrometeor conversion terms. Second, the basis for most bulk parameterization schemes (e.g., Lin et al. 1983; Rutledge and Hobbs 1983, 1984) was developed approximately $20 \mathrm{yr}$ ago when coarser resolution models were in use. More details of microphysical processes (such as fallout or conversions between hydrometeor categories) and their relationships to the convection producing them can now be resolved. Finally, more observations of tropical cyclones are now available (e.g., Black and Hallett 1986, 1999) making such a study possible.

In many bulk microphysical schemes (Lin et al. 1983; Rutledge and Hobbs 1983, 1984; Dudhia 1989; Rotstayn 1997; Reisner et al. 1998), ice-phase hydrometeors are sorted into three different categories: snow, graupel, and cloud ice. A mass-weighted terminal velocity $V_{m}$ is calculated separately for each category. The rates of conversions between liquid and solid hydrometeor categories heavily depend on this estimate of $V_{m}$, which is typically predicted using relationships from Locatelli and Hobbs (1974) that describe the fall velocities of individual snow and graupel particles. For example, the Reisner et al. (1998) microphysical scheme used in the fifth generation Pennsylvania State University-National Center for Atmospheric Research (PSU-NCAR) Mesoscale Model (MM5) assumes that the fall speed of snow particles can be adequately described by relationships developed using observations of the fall speeds of unrimed radiating assemblages of plates, side planes, bullets, and columns. Such relationships do not represent all situations. In tropical cyclones, most snow particles exhibit some degree of riming because ice particles begin as rimed particles in the convective regions, and then grow somewhat by diffusion in the stratiform regions; hence the relationships for unrimed radiative assemblages may not be applicable.

Microphysical data collected during penetrations of the National Oceanic and Atmospheric Administration
(NOAA) P-3 aircraft into hurricanes are used here to determine the relative importance of hydrometeor size, shape, and density for determining $V_{m}$. Snow and graupel are emphasized in this study because their fall speeds are more appreciable than that of ice and because their representation significantly impacts hurricane simulations. The effect of an inconsistency in the diameter used to define the size distributions and fall speeds of individual particles, first noted by Potter (1991), is examined as well as the importance of a discontinuity in the relationships used to define the fall speeds of individual particles (Khvorostyanov and Curry 2002). Finally, a new parameterization for $V_{m}$ is produced using observations that describe tropical cyclones. Some preliminary studies of this nature have already been conducted. For example, Braun and Tao (2000) modified the Goddard microphysical scheme (Tao et al. 1989; Tao and Simpson 1993) in their simulations of Hurricane Bob to more accurately represent conditions observed in tropical cyclones. Note that although the slopes and intercepts calculated here to describe the size distributions apply only to tropical cyclones, the general approach of ensuring consistency in diameter definitions is applicable to microphysical parameterizations used in simulations of any meteorological phenomena.

The remainder of the paper is organized as follows. In section 2 the relative importance of size, shape, and diameter definition for the calculation of $V_{m}$ is examined; in section 3 the in situ measurements that were collected in tropical cyclones are described; and in section 4 these observations are used to develop a new representation for size distributions, which includes a dependence on convective activity, that can be used in bulk microphysical schemes and that can be used to calculate $V_{m}$. The significance of these results is discussed in section 5 .

\section{Importance of size and shape for calculating mass-weighted fall speed}

\section{a. Approach}

In the aforementioned papers describing bulk cloud microphysical schemes used in mesoscale models, expressions for mass-weighted fall speeds of hydrometeor populations are developed and are given by

$$
V_{m}=\frac{\int_{0}^{\infty} V(D) m(D) N(D) d D}{\int_{0}^{\infty} m(D) N(D) d D},
$$

where $V(D)$ represents the terminal velocity of an individual particle, $m(D)$ represents hydrometeor mass, and $N(D)$ is the number density. Assumptions about $V(D), m(D)$, and $N(D)$ must be made in order to determine $V_{m}$. A detailed examination of the validity of some commonly used assumptions is made in this sec- 
tion. First, a traditional approach of calculating $V_{m}$ is reviewed.

In most parameterizations, fall speed-diameter relations proposed by Locatelli and Hobbs (1974) are used, and are represented by

$$
V(D)=a D^{b}\left(\frac{P_{0}}{P}\right)^{0.4}
$$

where $a$ and $b$ are habit, density, or size-dependent fit coefficients that differ for snow and graupel; $D$ is typically the maximum particle dimension $D_{\max }$ of the hydrometeor; $P$ is the atmospheric pressure; and $P_{0}$ is a constant given by $10^{6} \mathrm{~N} \mathrm{~m}^{-2}$. It should be noted that the parameterized dependence on pressure is an ad hoc approximation to the real change in velocities with pressure. Because analytic integration of Eq. (1) is desired for bulk parameterization schemes, it is conventionally assumed that $a$ and $b$ are constant. The suitability of this assumption is discussed later. Typically, $m(D)$ is represented by

$$
m(D)=\frac{\pi}{6} \rho D^{3},
$$

where $\rho$ represents the bulk density, defined as particle mass divided by particle volume, of snow $\left(\rho_{s}\right)$ or graupel $\left(\rho_{g}\right)$; and $D$ is the volume equivalent diameter $D_{\text {vol }}$ of the hydrometeor. The size distribution $N(D)$ is represented by an exponential function

$$
N(D)=N_{0} \exp (-\lambda D),
$$

where $N_{0}$ and $\lambda$ are the intercept and slope for the fit, which again differ for snow $\left(N_{0 s}\right.$ and $\left.\lambda_{s}\right)$ and graupel $\left(N_{0 g}\right.$ and $\lambda_{g}$ ). In Eq. (4), $D$ can be $D_{\text {vol }}, D_{\max }$, or melted equivalent diameter $D_{\text {melt }}$, depending on the source of observations. Ignoring differences in diameter definitions between equations, and assuming that $a$ and $b$ are known and independence of hydrometeor size, an analytic expression for $V_{m}$ may be written as (e.g., Rutledge and Hobbs 1983)

$$
V_{m}=\frac{a \Gamma(4+b)}{6 \lambda^{b}}\left(\frac{P_{0}}{P}\right)^{0.4} .
$$

This analytic expression can be incorporated into models without explicit integration, allowing for minimal computational time.

Potter (1991) was the first to point out the inconsistency between diameter definitions used in the development of such bulk parameterizations. This inconsistency makes the use of Eq. (5) inappropriate. An improved relation for $V_{m}$ is developed here by properly combining expressions for exponential hydrometeor size distributions in terms of $D_{\text {melt }}$ (e.g., Gunn and Marshall 1958; Sekhon and Srivastava 1970) with published relationships for $V(D)$ (e.g., Locatelli and Hobbs 1974; Mitchell 1996; Heymsfield and Iaquinta 2000; Khvorostyanov and Curry 2002) that give velocity in terms of $D_{\max }$, or on occasion, the diameter of a spherical particle with the same projected area $D_{\text {area }}$. Similar combinations of size distributions have been used in the past development of mesoscale parameterization schemes (e.g., Lin et al. 1983; Reisner et al. 1998), but differences in diameter definitions have not been commonly considered. The major problem with this inconsistency is not that an exponential distribution in terms of $D_{\text {melt }}$ is not strictly an exponential distribution in terms of $D_{\max }$, but rather than the parameters of the best-fit exponential distribution will vary substantially for functions in terms of $D_{\text {melt }}$ and $D_{\max }$. The $a$ and $b$ coefficients describing hydrometeor fall velocities also vary significantly depending on whether the parameterization is in terms of $D_{\text {melt }}$ or $D_{\max }$. Other studies have derived exponential size distributions in terms of $D_{\max }$ for snow and ice (e.g., Braham 1990; Houze et al. 1979; Herzegh and Hobbs 1985; Ryan 2000) and for graupel (Houze et al. 1979), which permit more of a straightforward application of Eq. (1), provided that the effective density, mass divided by volume of sphere with diameter of maximum particle dimension, is used in Eq. (3) rather than the bulk density.

To develop an internally consistent representation of $V_{m}$, mass-diameter relationships of the form

$$
m(D)=\alpha D^{\beta}
$$

are used, where $\alpha$ and $\beta$ are coefficients that depend on size, shape, and density of the snow and graupel. Using a wide range of observations of particle mass, and $\alpha, \beta$ coefficients derived by various authors, Mitchell (1996) catalogs $\alpha$ and $\beta$ for a variety of different particles types. Combining these relationships with expressions for particle fall speeds in terms of maximum dimension, a new velocity relationship for individual particles is derived as $V\left(D_{\text {melt }}\right)=a^{\prime} D_{\text {melt }}^{b^{\prime}}\left(P_{0} / P\right)^{0.4}$, where

$$
a=a\left(\frac{\pi \rho_{w}}{6 \alpha}\right)^{b / \beta} \text { and } \quad b^{\prime}=\frac{3 b}{\beta} .
$$

Further, the mass of the melted equivalent particles used to characterize the exponential distributions is expressed in terms of the density of water $\rho_{w}$ as $m\left(D_{\text {melt }}\right)=$ $\pi \rho_{w} D_{\text {melt }}^{3} / 6$. Substituting $V\left(D_{\text {melt }}\right)$ and $m\left(D_{\text {melt }}\right)$ in Eq. (1), and assuming exponential distributions in terms of $D_{\text {melt }}$, gives

$$
V_{m}=\frac{a\left(\frac{\pi \rho_{w}}{6 \alpha}\right)^{b / \beta} \Gamma\left(4+\frac{3 b}{\beta}\right)}{6 \lambda_{\text {melt }}^{3 b / \beta}}\left(\frac{P_{0}}{P}\right)^{0.4},
$$

where $\lambda_{\text {melt }}$ is $\lambda$ defined in terms of $D_{\text {melt }}$. Equation (8) is still an analytic expression for $V_{m}$ and is based on typical velocity coefficients in terms of $D_{\max }$, and can be easily applied in numerical models. For cases where the size distributions of observed particles are parameterized in terms of $D_{\max }$, with slope $\lambda_{\max }$, an alternate expression for $V_{m}$ can be derived as 


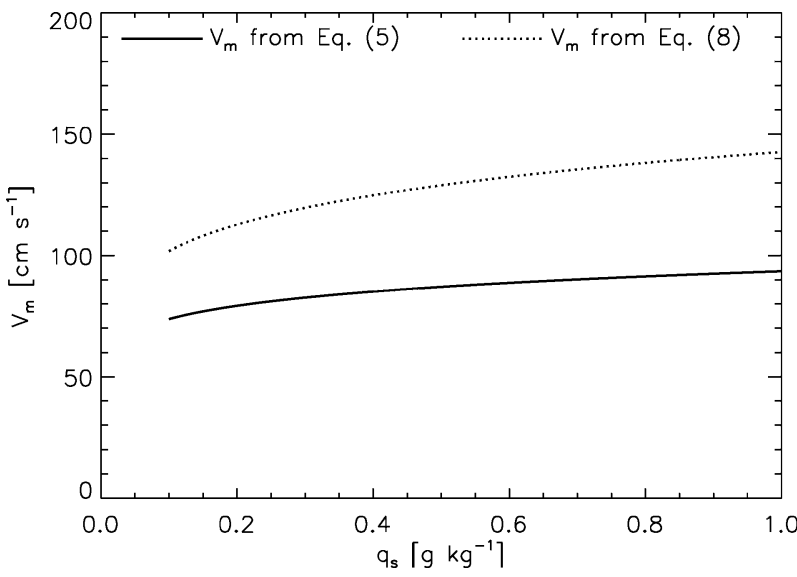

FIG. 1. Terminal velocity $V_{m}$ is a function of $q_{s}$ using $(a, b)$ coefficients from Mitchell (1996) describing unrimed assemblages of columns, plates, side planes, and aggregates. Dashed line represents $V_{m}$ calculated using Eq. (8) (i.e., no inconsistency in diameter definitions); solid line, using Eq. (5) (i.e., that used by majority of microphysical parameterization schemes).

$$
V_{m}=\frac{a \Gamma(1+b+\beta)}{\lambda_{\max }^{b} \Gamma(1+\beta)}\left(\frac{P_{0}}{P}\right)^{0.4} .
$$

Brown and Swann (1997) considered the role of varying $\alpha, \beta, a$, and $b$ coefficients in their single moment microphysical scheme based on $D_{\max }$, but did not specifically present a generalized form of Eq. (9) in their paper. Caution must be taken to use either Eq. (8) or Eq. (9) depending on the form of the particle observations.

\section{b. Effects due to diameter discrepancies}

Figure 1 compares $V_{m}$ calculated for distributions of snow particles using Eqs. (8) and (5), the latter representing older parameterizations. A pressure equal to $P_{0}$ is used in the calculations. For typical one-moment parameterization schemes, $N_{0}$ is assumed constant meaning that $\lambda_{\text {melt }}$ must vary with the mixing ratio. Integrating an expression for mixing ratio gives

$$
\lambda_{\text {melt }}=\left(\frac{6 \rho_{w} N_{0}}{\rho_{a} q}\right)^{1 / 4} .
$$

For $V_{m}$ calculated using Eq. (5), $\lambda$ is defined differently following relationships used in traditional bulk parameterization schemes [e.g., Eq. (3b) of Rutledge and Hobbs 1983] that do not account for the different diameter definitions discussed here. For Fig. 1, snow particles are exponentially distributed with a constant $N_{0}$ of $2.0 \times 10^{7} \mathrm{~m}^{-4}$, and snow mass mixing ratio $q_{s}$ varies over ranges typically observed in tropical cyclones.

Figure 1 shows that failing to correct for the diameter discrepancy, and hence the values of both $\lambda$ and $V(D)$, can cause a significant underestimate of $V_{m}$ for snow; the underestimate is not as large for graupel because graupel more closely approximate shapes and the $\beta$ coefficients are closer to 3 . The trend noted in Fig. 1 is opposite that noted by Potter (1991), who found that correcting for diameter discrepancies gave a decrease in $V_{m}$. The difference is related to the manner in which Potter (1991) applied the correction, using mass-velocity relationships derived by Locatelli and Hobbs (1974) to obtain the corrected $V_{m}$. A combination of previously published $m-D, m-V$, and $m-D$ relationships do not yield consistent results suggesting that there are observational uncertainties associated with the derivation of the $a$ and $b$ coefficients. The curves in Fig. 1 are not extended below $q_{s}$ of $0.1 \mathrm{~g} \mathrm{~kg}^{-1}$ because at such low mixing ratios, many smaller particles would be prevalent and the assumed constant $a$ and $b$ values would not apply to these particles. A further examination on the size dependence of $a$ and $b$ is discussed below; Fig. 1 merely shows the importance of a consistent diameter definition.

Despite the apparent importance of the inconsistencies noted by Potter (1991), only very few remote sensing studies (e.g., Braun and Houze 1995) and parameterization schemes (Ferrier 1994) have implemented such corrections. These corrections have most likely not been incorporated into models because there are other inconsistencies in conversion rates between hydrometeor categories that also need to be addressed for the parameterizations to be consistent. For example, when calculating the conversion of cloud water to snow by riming (PSACI), a term is required that involves the geometric sweep out of a volume of cloud by a snowflake. This term should be expressed by

$$
\begin{aligned}
\text { PSACI } & =\int_{0}^{\infty} N_{0 s} e^{-\lambda_{s} D_{s}} \frac{d M\left(D_{s}\right)}{d t} d D_{s}, \\
\frac{d M\left(D_{s}\right)}{d t} & =\frac{\pi}{4} \rho_{a} D_{\mathrm{sa}}^{2} V\left(D_{s}\right) q_{i} E_{\mathrm{SI}},
\end{aligned}
$$

where the $s$ subscript represents snow, $E_{\mathrm{SI}}$ is the snow/ cloud ice collection efficiency, and $D_{\mathrm{sa}}$ is the area-equivalent diameter of snow. The use of $D_{\text {sa }}$ allows more accurate representations of geometric sweep out of cloud ice, which has mass mixing ratio $q_{i}$. Mitchell (1996) defines relationships between projected area $A_{P}$ and $D_{\max }$ of the form

$$
A_{P}=\gamma D_{\max }^{\sigma},
$$

where $\gamma$ and $\sigma$ are coefficients that vary according to the size, shape, and density of snow $\left(\gamma_{s}\right.$ or $\left.\sigma_{s}\right)$ or graupel $\left(\gamma_{g}\right.$ or $\sigma_{g}$ ). Equation (12) allows calculation of $D_{\text {area }}$ by substituting $A_{P}=\pi D_{\text {area }}^{2} / 4$. Hence, PSACI can be expressed as

$$
\begin{aligned}
\text { PSACI }= & a_{s} \rho_{a} \gamma_{s} N_{0 s} q_{i} E_{\mathrm{SI}}\left(\frac{\rho_{w} \pi}{6 \alpha_{s}}\right)^{\left(\sigma_{s}+b_{s}\right) / \beta_{s}} \\
& \times \frac{\Gamma\left[1+\frac{\left.3 \sigma_{s}+b_{s}\right)}{\beta_{s}}\right]}{\lambda_{s}^{1+3\left(\sigma_{s}+b_{s}\right) / \beta_{s}}}\left(\frac{P_{0}}{P}\right)^{0.4},
\end{aligned}
$$



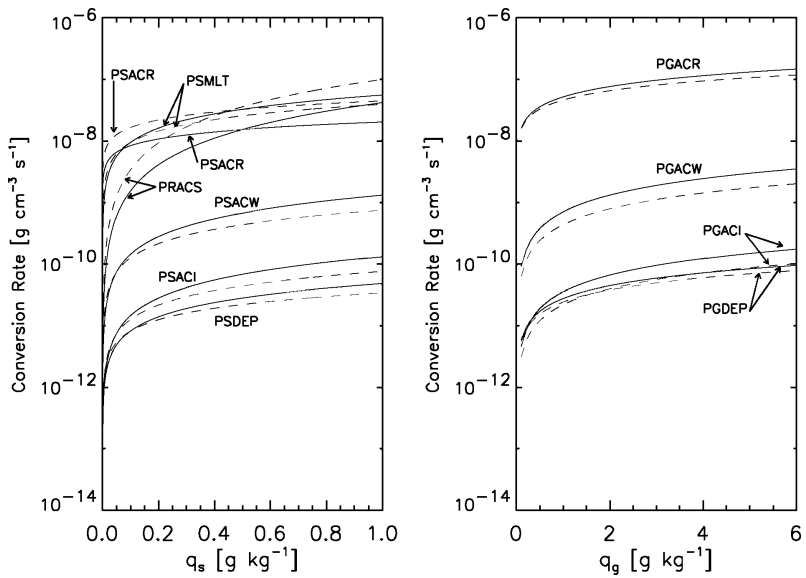

FIG. 2. Conversion rates between different hydrometeor categories (snow, graupel, cloud ice, cloud water, and rain). Solid lines represent rates after corrections made to account for inconsistencies in diameter definitions used by schemes, and to account for calculation of geometric sweep out in terms of area-equivalent diameter; dashed lines are rates using Reisner et al.'s (1998) scheme without these corrections. Reisner et al. (1998) and appendix A give equations used, text describes cloud conditions assumed.

which differs from Eq. (A43) of Reisner et al. (1998). Similar expressions for processes that convert mass between other hydrometeor categories are also derived and are summarized in appendix A; all terms and symbols are defined as in Reisner et al. (1998) and for simplicity it has been assumed that the pressure is equal to $P_{0}$. Although more complex in form than the original equations, listed in appendix B all equations are easily integrable and require no extra computational expense. Therefore, there seems to be no reason not to use these more accurate equations. Figure 2 compares the magnitude of the conversions between the hydrometeor categories as a function of $q_{s}$ or graupel mixing ratio $q_{g}$ calculated by both applying and not applying the corrections noted above. The calculations are based upon temperatures similar to those observed in tropical cyclones near the melting layer, namely, for a temperature of $-5^{\circ} \mathrm{C}$; pressure of $700 \mathrm{~m}$; and assuming rainwater $q_{R}$ and cloud mixing ratios $q_{c}$ of 1.0 and $0.1 \mathrm{~g} \mathrm{~kg}^{-1}$, respectively. Differences between terms of at least a factor of 2, and sometimes more, frequently exist. A more detailed modeling or observational study is needed to calculate average differences using simulated values of mixing ratios and densities, rather than using the simple assumptions used to construct Fig. 2. The curves are extended to low values of $q_{s}$ and $q_{g}$, where assumptions of constant $a$ and $b$ values may be questionable. Nevertheless, Fig. 2 does show that these correction terms should be considered for more accurate calculation of conversions between hydrometeor categories.

\section{c. Effect of uncertainties in $(a, b)$ coefficients}

Another uncertainty associated with the model representation of $V_{m}$ is the choice of $(a, b)$ coefficients

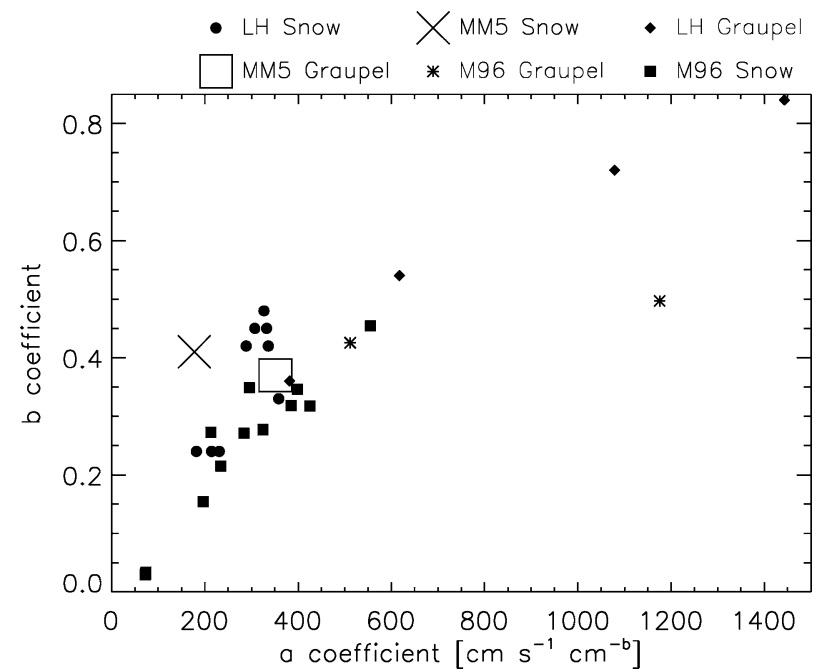

FIG. 3. Scatterplot of $(a, b)$ coefficients used to describe fall speed of snow and graupel particles in terms of $V=a D_{\text {melt }}^{b}$. Different symbols correspond to observations of graupel and snow made by Locatelli and Hobbs (LH) and Mitchell (M96). The $\times$ and big square indicate values for snow and graupel, respectively, currently used by the Reisner et al. (1998) scheme of MM5 model.

describing the fall speeds of snow and graupel particles. Typically, single values of $(a, b)$ are used in simulations, but in reality, $(a, b)$ vary according to the shapes and densities of snow and graupel and their size (Mitchell 1996). Based on Locatelli and Hobbs (1974) and Mitchell (1996), Fig. 3 shows the range of $(a, b)$ coefficients that might be used to describe the fall of snow and graupel. The plotted coefficients are not the values from the original papers, but rather are the $\left(a^{\prime}, b^{\prime}\right)$ values given by Eq. (7) to characterize $V$ in terms of $D_{\text {melt }}$. The values used in the Reisner et al. (1998) microphysical scheme for snow and graupel, as incorporated in MM5, are shown for comparison. For the same shape, there are different $(a, b)$ values from Mitchell (1996) depending on particle diameter; values of $(a, b)$ corresponding to the largest snowflakes are plotted in Fig. 3 because analysis of Sekhon and Srivastava's (1970) parameterized snowflake size distributions shows that the majority of the mass would be contained in these sizes. Note that coefficients that are used to describe the fall velocities of monohabit pristine crystals, with typical sizes smaller than $100 \mu \mathrm{m}$, are not included in Fig. 3 because such crystals would be represented as ice in typical numerical models (e.g., the minimum radius of a snow crystal is $75 \mu \mathrm{m}$ in MM5), and their fall speeds are negligible. This exclusion is important because mass-diameter and velocity-diameter relationships may provide unrealistic results for sizes smaller than 100 mm, and corrections are needed (e.g., Brown and Francis 1995). Analysis of both the tropical cyclone data collected here and Sekhon and Srivastava's (1970) parameterized distributions confirm that little mass is included in sizes below $100 \mu \mathrm{m}$ for snow and graupel, 
hence such corrections are not as important for this study.

Substantial spread in $(a, b)$ values is noted in Fig. 3 because of the wide variety of crystal habits or mixtures of habits that make up the snow category and because of variations in the shape and densities of graupel. For example, from Locatelli and Hobbs (1974), the $(a, b)$ values for lump graupel vary from $\left(0.45,332 \mathrm{~cm}^{0.55}\right.$ $\left.\mathrm{s}^{-1}\right)$ to $\left(0.72,1078 \mathrm{~cm}^{0.28} \mathrm{~s}^{-1}\right)$ to $\left(0.36,382 \mathrm{~cm}^{0.64} \mathrm{~s}^{-1}\right)$ for bulk densities between 0.05 to $1,0.1$ to 0.2 , and 0.2 to $0.45 \mathrm{~g} \mathrm{~cm}^{-3}$. Density measurements are not available for many of the different snow crystal data, but it is likely that density variation also causes some of this variation in $(a, b)$. This variation in $(a, b)$ coefficients may have important ramifications for the simulation of tropical cyclones. Black (1990) noted substantial gradients in the densities of snow and graupel particles with larger densities closer to the hurricane eyewall. Hence, it may be possible that varying $(a, b)$ coefficients should be used in the single simulation of a tropical cyclone. Khvorostyanov and Curry (2002) also developed an analytic function that describes the variation in $(a, b)$ with particle size; variation of mean size might therefore also affects the calculation of $V_{m}$.

Figure 4 shows that variations in $(a, b)$ have important ramifications for the calculation of $V_{m}$. The massweighted terminal velocity is plotted as a function of $N_{0}$, with different line types representing varying $(a, b)$ coefficients, with some line types repeated for snow. Thin and thick lines correspond to different $q_{g}(0.5$ and $\left.5 \mathrm{~g} \mathrm{~kg}^{-1}\right)$ and $q_{s}\left(0.02\right.$ and $\left.0.5 \mathrm{~g} \mathrm{~kg}^{-1}\right)$, with the thicker lines representing higher mixing ratios. The slope of the exponential distribution in terms of $D_{\text {melt }}$ is determined following Eq. (10) to ensure consistency. It can be seen that the choice of $(a, b)$ is just as important as the choice of $N_{0}$ for determining $V_{m}$; for example, for $N_{0 g}$ of 1.0 $\times 10^{8} \mathrm{~cm}^{-4}, V_{m}$ for low-density lump graupel is only $137 \mathrm{~cm} \mathrm{~s}^{-1}$, whereas $V_{m}$ for conical graupel is $287 \mathrm{~cm} \mathrm{~s}^{-1}$.

Because of variations in the relationship between the Reynolds and Best number depending on fall regime, Mitchell (1996) parameterized $(a, b)$ to vary with particle size. Khvorostyanov and Curry (2002) developed an analytic expression for the variation of the $(a, b)$ coefficients that avoided the step functions or discontinuities in the Mitchell (1996) scheme, but their expressions still do not allow for an analytic expression for $V_{m}$. Hence, an examination was made using Mitchell's (1996) study of the size variation of $a$ and $b$ coefficients to determine errors induced by assuming constant values of $a$ and $b$. It is implicitly assumed that the Mitchell (1996) stepwise relations adequately characterize the size variation of the fall speed coefficients.

Performing an analytic integration over the observed snow and graupel size distributions collected in tropical cyclones, to be discussed in section 3, allows a determination of whether these variations of $(a, b)$ with particle size are important. Figure 5 compares $V_{m}$ calculated using nonvarying values of $(a, b)$ against $V_{m}$ calculated
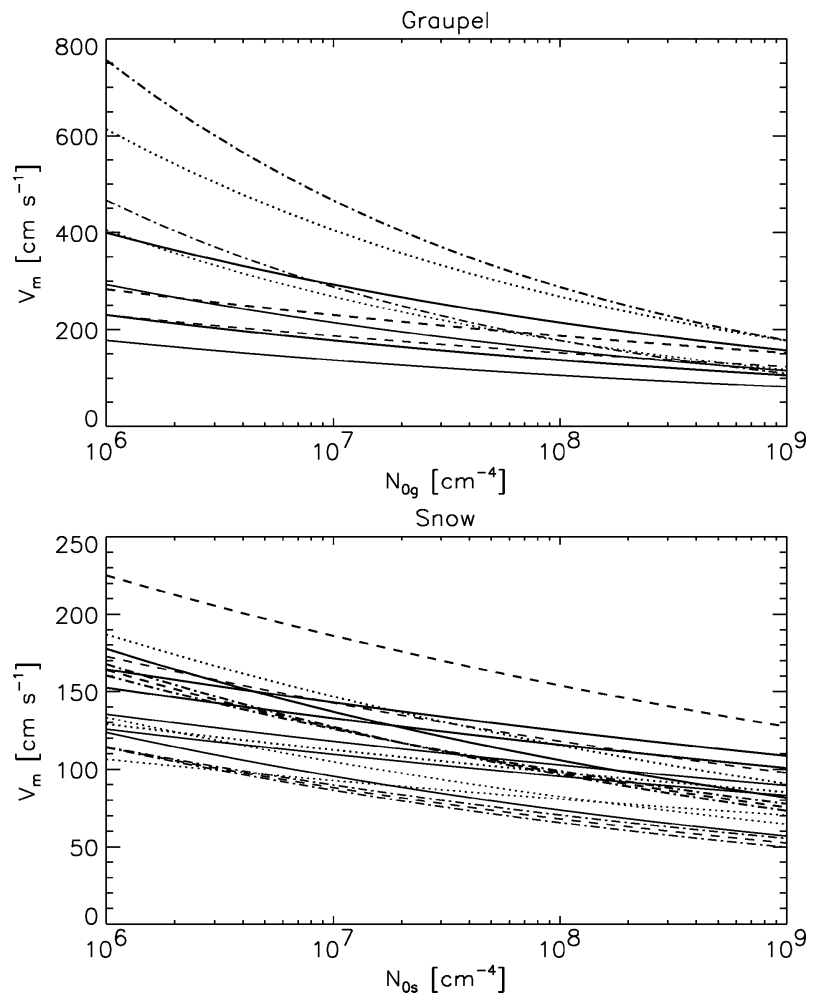

FIG. 4. Terminal velocity $V_{m}$ is a function of $N_{0}$ for (top) graupel and (bottom) snow distributions. Different line types correspond to different $(a, b)$ coefficients, obtained from Locatelli and Hobbs (1974) but converted into expressions in terms of $D_{\text {melt }}\left(V=a D_{\text {melt }}^{b}\right)$. Note $\left(a_{p}, b_{g}\right)$ values given by $(332,0.45)$ for solid, $(1078,0.72)$ for dotted, $(381,0.36)$ for dashed, $(1443,0.84)$ for dashed-dotted, and $(617$, $0.54)$ for dash-dot-dot. Note $\left(a_{s}, b_{s}\right)$ values given by $(231,0.24)$ and (332, 0.45) for solid, $(336,0.42)$ and $(182,0.24)$ for dotted, (359, $0.33)$ and $(307,0.45)$ for dashed, $(327,0.48)$ and $(307,0.45)$ for dashed-dotted, and $(215,0.24)$ for dash-dot-dot. Thick lines represent calculations for $q_{s}$ of $0.5 \mathrm{~g} \mathrm{~kg}^{-1}$ and $q_{g}$ of $5 \mathrm{~g} \mathrm{~kg}^{-1}$. Thin lines represent $q_{s}$ of $0.02 \mathrm{~g} \mathrm{~kg}^{-1}$ and $q_{g}$ of $0.5 \mathrm{~g} \mathrm{~kg}^{-1}$.

using a Simpson's rule integration that accounts for the variation of $(a, b)$ coefficients following Mitchell (1996). Note that the $(a, b)$ chosen for the comparison give the closest match to the analytically calculated $V_{m}$. The different points represent calculations for varying $N_{0}$ values and for varying $(a, b)$ using the values tabulated by Mitchell (1996). There are only minor differences between the two calculations, with average differences of $3.5 \% \pm 2.2 \%$ for snow and $1 \% \pm 2 \%$ for graupel. Hence, given other uncertainties in the calculation of $V_{m}$, it is not necessary to account for the variation of $(a, b)$ coefficients with particle size for these observed size distributions provided that $(a, b)$ coefficients, based on those values where the majority of hydrometeor mass is located, are used. This occurs because the majority of the mass in the snow and graupel size distributions occurs for the specific Reynolds/Best number regime given by Mitchell (1996). The choice of ( $a$, $b$ ) coefficients for the calculation of $V_{m}$ may depend on the size distribution or hydrometeor category being ex- 


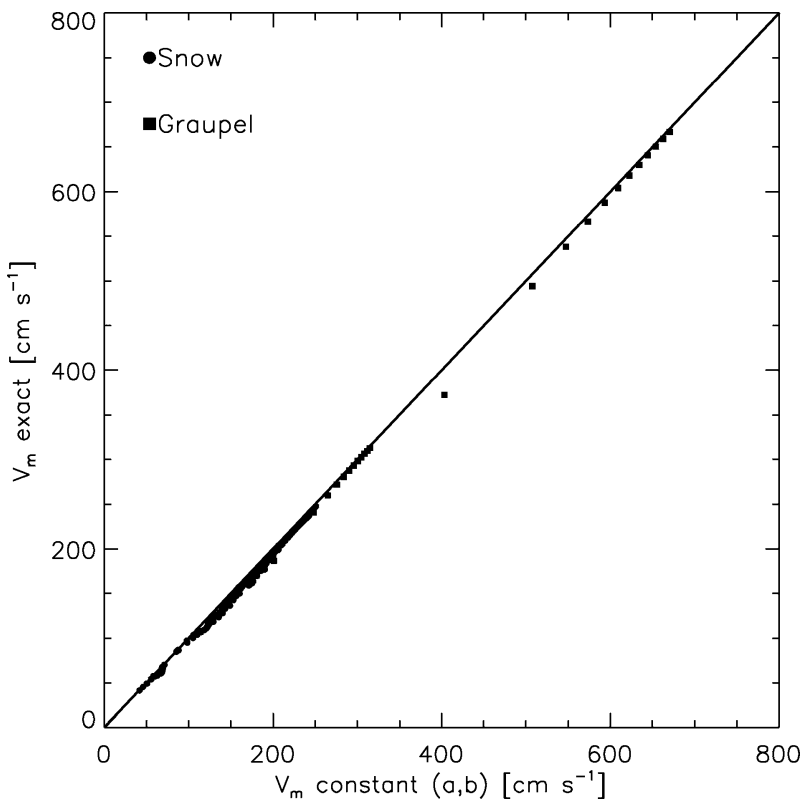

FIG. 5. Terminal velocity $V_{m}$ is calculated using $(a, b)$ coefficients that vary with particle size following Mitchell (1996) against $V_{m}$ calculated assuming a constant $(a, b)$. The constant $(a, b)$ are chosen as those values in Mitchell's (1996) step functions that give $V_{m}$ closest to that calculated considering the variation of $(a, b)$. The calculated values correspond to $q_{g}$ between 0.5 and $5 \mathrm{~g} \mathrm{~kg}^{-1}$, and to $q_{s}$ between 0.02 and $1 \mathrm{~g} \mathrm{~kg}^{-1}$. All $(a, b)$ coefficients listed in Mitchell's (1996) Table 1 are used in calculations, after conversion using Eq. (7).

amined; for example, Sekhon and Srivastava's (1970) size distribution has more contributions from large snow than do the observations presented here from tropical cyclones, and therefore the use of different $(a, b)$ coefficients might be appropriate.

At first glance, it might appear that Fig. 5 shows that $(a, b)$ coefficients are unaffected by variation in the sizes of snow or graupel. However, this is not the case. For example, the Mitchell (1996) coefficients for the larger particle sizes and Reynolds number are always associated with smaller $(a, b)$ values than those coefficients for smaller particle sizes. Figure 6 shows that, despite considerable scatter, such a general trend also exists when comparing the $(a, b)$ coefficients for different shapes and sizes of snow using both the Mitchell (1996) and Locatelli and Hobbs (1974) coefficients. Matrosov and Heymsfield (2000) also demonstrated this and parameterized these relations, and this is also seen from Khvorostyanov and Curry's (2002) parameterization. Examination of $(a, b)$ values also shows that aggregate crystals typically have smaller $(a, b)$ coefficients than do monohabit pristine ice crystals for the habits described by Locatelli and Hobbs (1974) and Mitchell (1996). Because aggregates are larger than those pristine crystals, this shows further evidence of the size-dependent trends of the $(a, b)$ coefficients. Hence, if different parts of clouds have differing size distributions or particle sizes, the $(a, b)$ coefficients might be expected to
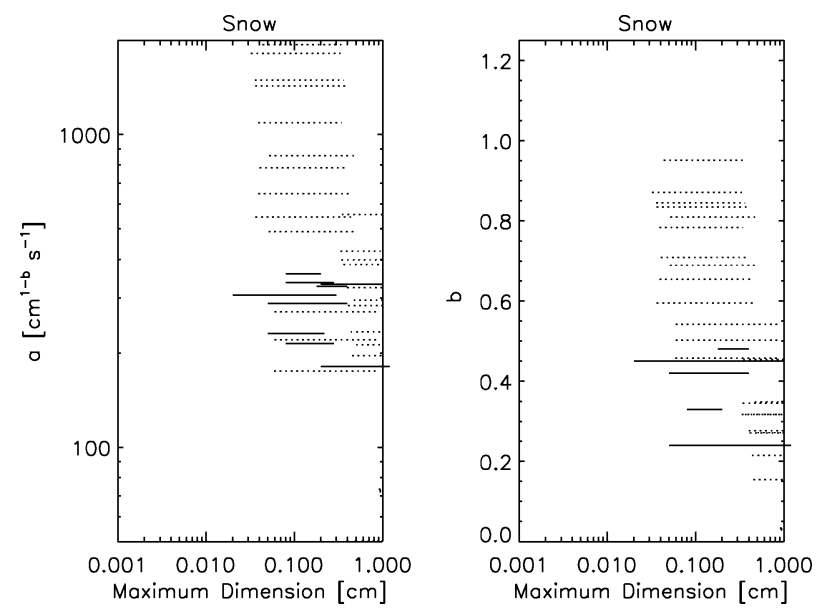

FIG. 6. Variation of $(a, b)$ coefficients, in terms of $D_{\text {melt }}$, obtained from Locatelli and Hobbs (1974; solid lines), and Mitchell (1996; dashed lines), as function of $D_{\max }$. General trend for decrease of $a$ and $b$ with increasing particle size is seen.

differ, and a proper choice of $(a, b)$ coefficients should be made to reflect this.

Examination of a similar figure for graupel did not clearly exhibit such trends. Locatelli and Hobbs (1974) list three separate relationships for lump graupel depending on density and separate relationships for conical and hexagonal graupel, and there is no clear dependence on size; density variations dominate the relationships. This, plus the scatter in Fig. 6, shows that variations in $(a, b)$ with size alone is not sufficient to understand the behavior; variations due to different densities and shapes must also be accounted for in parameterization development for numerical models.

Hence, to develop a new parameterization of $V_{m}$, the variation of $(a, b)$ with mean particle size, with particle shape, with density, and with other known effects must be accounted for. In reality, all effects combined mean that a single $(a, b)$ pair is not adequate for use in a numerical model. Extra information from in situ observations, remote sensing, or other sources might be required to deduce more representative $(a, b)$ coefficients; further, probability distributions may be needed to characterize ranges of $(a, b)$ coefficients because information on the frequency of occurrence of different snow crystal shapes is not well known, and the percentages of different shapes varies depending on cloud formation mechanism, geographic location, temperature, and other factors (Heymsfield and McFarquhar 2002). It is also important to know particle size distributions, namely, the intercept and slope parameter used to characterize the exponential distribution. In the next section, in situ observations obtained in tropical cyclones are used to help develop a $V_{m}$ parameterization that can be implemented in numerical models.

\section{In situ observations in tropical cyclones}

Black (1990), Black and Hallett (1985, 1999), and Black et al. (1994) describe the platforms and instru- 
ments used to collect in situ observations of particle shapes and sizes in tropical cyclones. During the $20 \mathrm{yr}$ prior to 1992, two-dimensional cloud (2DC) and precipitation (2DP) probes were installed on the NOAA P3 aircraft, which routinely flew approximately $80-\mathrm{km}-$ long radial legs through hurricanes at or just above the melting layer. In Fig. 1 of Black et al. (1990) an example is shown of a typical flight track made through Hurricane Emily. Because of inherent difficulties in making microphysical observations in such an environment, data are not available from all flights. In this study, microphysical data collected in two hurricanes [Norbert (1984), Emily (1987)] are used. These cases are selected for analysis as they represent some of the highest quality microphysical data collected in the past $20 \mathrm{yr}$ and are readily available.

Observations made in Hurricane Norbert (1984) and Hurricane Emily (1987) also represent two different types of conditions that may be encountered in hurricanes. Most of the data collected on 24 September 1984 in eastern Pacific Hurricane Norbert were obtained in stratiform areas outside the eyewall (Black 1990) and there was little strong convection anywhere in the storm. On the other hand, unusually strong updrafts and downdrafts were documented in the eyewall of Hurricane Emily on 22 September 1987 during its rapidly deepening phase (Black et al. 1994). Measurements were sampled at temperatures between $-11^{\circ}$ and $1{ }^{\circ} \mathrm{C}$ in Hurricane Norbert, and between $-7^{\circ}$ and $8^{\circ} \mathrm{C}$ in Hurricane Emily. During the flights, the pilots did not maneuver to either encounter or avoid heavy reflectivity regions, and hence the observations should be representative of conditions present in these particular hurricanes. Following Jorgensen et al. (1985), an updraft core is defined as a region where vertical motions were in excess of 1 $\mathrm{m} \mathrm{s}^{-1}$ for at least $4 \mathrm{~s}$, corresponding to a horizontal distance of approximately $0.5 \mathrm{~km}$. A downdraft core is similarly defined as regions with vertical velocities less than $-1 \mathrm{~m} \mathrm{~s}^{-1}$ for 4 consecutive seconds. Stratiform areas are those areas outside these convective updraft and downdraft regions. This is slightly different than the definition of Houze (1993), who defined stratiform regions as locations with air motions less than the mean terminal velocity of hydrometeors. The definition discrepancy does not affect subsequent analysis.

The microphysical data were collected using Particle Measuring Systems (PMS) 2DC and 2DP probes. Black and Hallett (1986) and Black (1990) describe the analysis procedures followed. Separate size distributions are generated for graupel, columns, liquid water, and cloud ice, hereafter snow, following an automated technique. The 2DC resolution for the storms considered is $50 \mu \mathrm{m}$, meaning that it could measure particles as large as 1600 $\mu \mathrm{m}$, and the 2DP resolution is $0.2 \mathrm{~mm}$, meaning that it could measure particles as large as $6.4 \mathrm{~mm}$. Any presumed ice particle whose outline is close to circular, as defined using measures of the image perimeter and area perimeter ratio, is called graupel; actual raindrops are
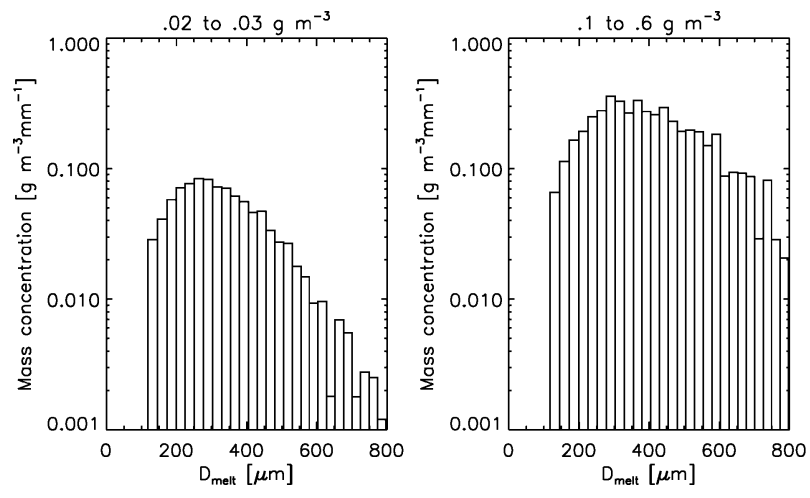

FIG. 7. Mass concentration of graupel as function of $D_{\text {melt }}$ for average size distribution computed from all graupel size distributions with graupel mass contents between 0.02 and $0.03 \mathrm{~g} \mathrm{~m}^{-3}$, and between 0.1 and $0.6 \mathrm{~g} \mathrm{~m}^{-3}$.

elliptical because of airflow distortions. Graupel is only identified from the 2DC data because the poor resolution of the 2DP caused a fairly high false positive rate; examination of mass size distributions showed that graupel particles larger than $1 \mathrm{~mm}$ were very rare.

The sample volumes of the 2DC and 2DP are approximately $10 \mathrm{~L} \mathrm{~s}^{-1}$ and $56 \mathrm{~L} \mathrm{~s}^{-1}$, respectively. The "center-in" technique, which accepts particles whose largest dimension is not on the edge of the array so long as there is nothing else wrong with them, is used to accept particles. Heymsfield and Parrish (1979) describe this technique and the required adjustments to sample volume. Because hydrometeor concentrations typically decrease with particle size, there might be a concern that statistically significant numbers of large hydrometeors would not have been measured, preventing computations of mass concentration and reflectivity factor dominated by large particles. Figure 7 shows average distributions of mass concentration for graupel with respect to $D_{\text {melt }}$ for all size distributions with graupel mass contents between 0.02 and $0.03 \mathrm{~g} \mathrm{~m}^{-3}$ and between 0.1 and $0.6 \mathrm{~g} \mathrm{~m}^{-3}$. There does not appear to be significant numbers of graupel particles missing from the observations as seen from the size distribution trends in the ranges that the probes cover, even for the highest graupel mass contents observed, suggesting that the probe data are adequate. In addition, flights by the NOAA P-3 in hurricanes over a 10 -yr period that used a $2 \mathrm{D}$ gray probe with a maximum size of $9.6 \mathrm{~mm}$ never encountered particles larger than the $6.4-\mathrm{mm}$ maximum size of the 2DP probe used here; the sample volume of the 2D gray probe used for these observations is approximately $50 \%$ larger than that of the 2DP probe used for the observations presented here. The turbulent flow inside a hurricane prevents the formation of giant fluffy snowflakes, and the updrafts are not strong enough to create hailstones. A similar plot of reflectivity factor $Z$ showed that, for mass contents between 0.02 and $0.03 \mathrm{~g} \mathrm{~m}^{-3} Z$ peaked at $450 \mu \mathrm{m}$, and for mass contents between 0.1 and $0.6 \mathrm{~g} \mathrm{~m}^{-3}, Z$ peaked around $600 \mu \mathrm{m}$. This suggests 


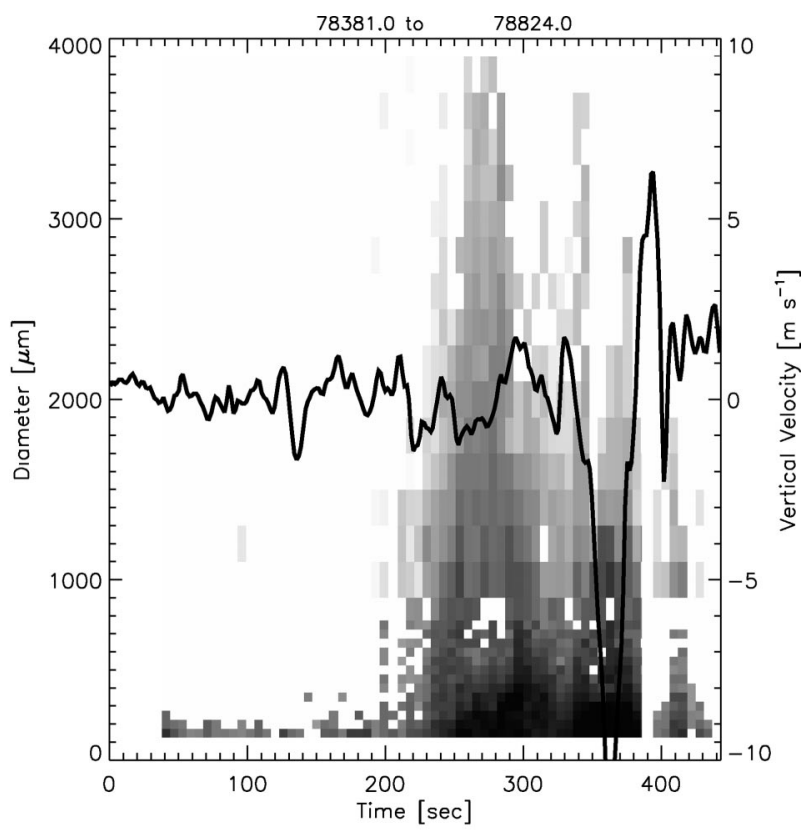

Number concentration $\left[1^{-1} \mathrm{~mm}^{-1}\right]$

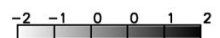

FIG. 8. Number concentration as function of diameter and as function of time since the start of penetration for a constant altitude flight leg made through Hurricane Emily on 22 Sep 1987 from 2146:21 to 2153:10 UTC. Size distributions obtained from composite of 2DC and 2DP data, and include contributions from all frozen and liquid hydrometeors. Solid line superimposed corresponds to vertical velocity deduced from aircraft measurements. Ambient temperature varied from $-4.3^{\circ}$ to $5.4^{\circ} \mathrm{C}$, with an average temperature of $-2.0^{\circ} \mathrm{C}$.

that the suite of probes are adequate for detecting contributions to mass and reflectivity, though a few large particles contributing to $Z$ may be missed.

Black (1990) describes a technique for estimating the effective particle densities from regression equations linking radar reflectivity and ice water content from airborne radar and particle image data. Because the probes appeared to measure both mass and reflectivity adequately, this approach should provide reasonable results. Typical densities using this approach ranged from about 0.01 to $0.55 \mathrm{~g} \mathrm{~cm}^{-3}$. The calculated $Z$ values will then match the measured $Z$ values because of the choice of effective density. This type of analysis is available for Hurricane Emily, but not for Hurricane Norbert. Hence, estimates of particle mass are probably within a factor of 2 (Black 1990) for Hurricane Emily, but only within a factor of 3 for Hurricane Norbert. Because snow typically dominates particle masses, and to ensure consistency between the two storms, graupel masses are estimated using mass-diameter coefficients described by Mitchell (1996).

Liquid water content is available for some of the Emily cases as measured by a Johnson-Williams (JW) cloud liquid water meter. To obtain estimates of vertical velocity, the dynamic pressure was filtered with a 5-s onesided filter in the forward direction, then backward in
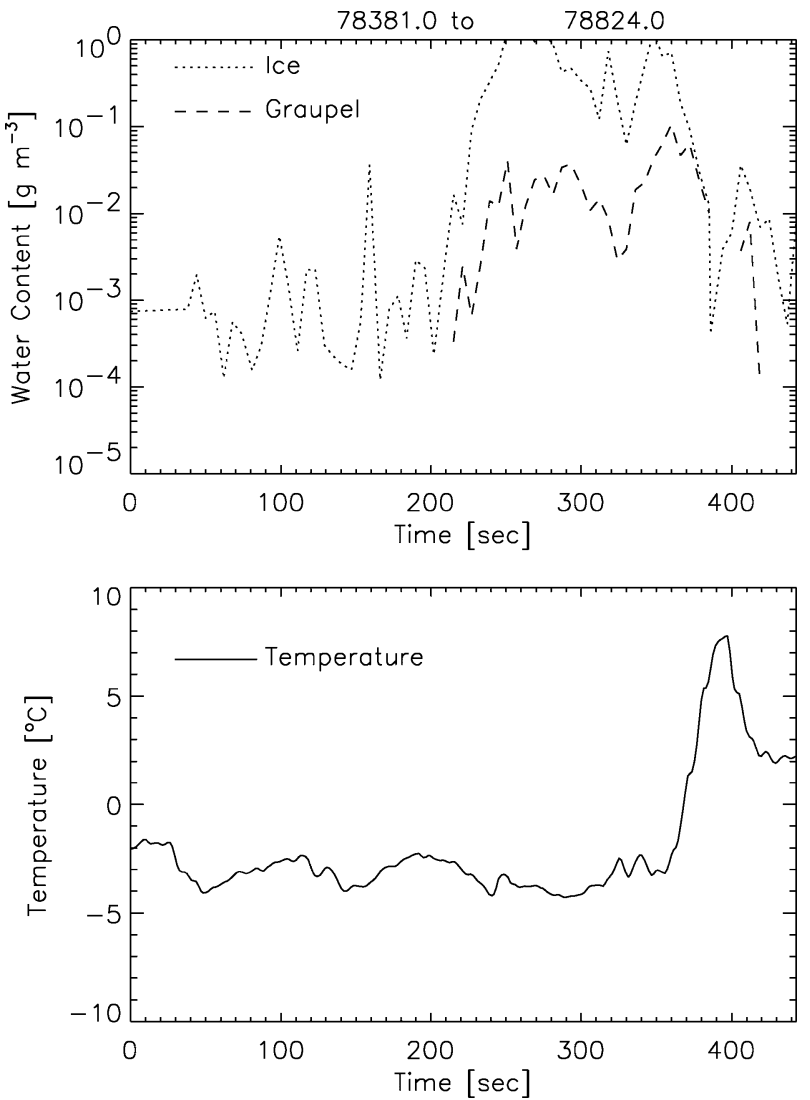

FIG. 9. (top) Graupel (dashed line) and ice (dotted line) water content as function of time for time period plotted in Fig. 8. (bottom) Temperature (solid line) also shown.

time with the same filter. These data were averaged to get a filtered vertical airspeed, the difference between this and the vertical aircraft speed computed from renavigated inertial navigation equipment (INE) data, being the vertical wind speed.

Figure 8 shows hydrometeor size distributions obtained during one radial leg through Hurricane Emily plotted as a function of time, with the estimated vertical velocity superimposed. These measurements were made near the freezing level. Despite an expectation of higher numbers of large and small hydrometeors in the convective zones, if anything, there is a trend to smaller number concentrations in these zones.

Large variations in the size distributions are seen on very short time scales in Fig. 8. Similar variations are seen in the other radial penetrations that were plotted in a similar manner (figures not shown). Black and Hallett (1999) also reported that strong updrafts containing cloud water and millimeter raindrops, but no graupel, could occur within a few hundred meters of downdrafts containing millimeter-diameter graupel, raindrops, and cloud water. Figure 9 shows the time variation of graupel and ice water contents as a function of time for the same time periods depicted in Fig. 8, together with the temperature. The plotted ice water field includes contri- 


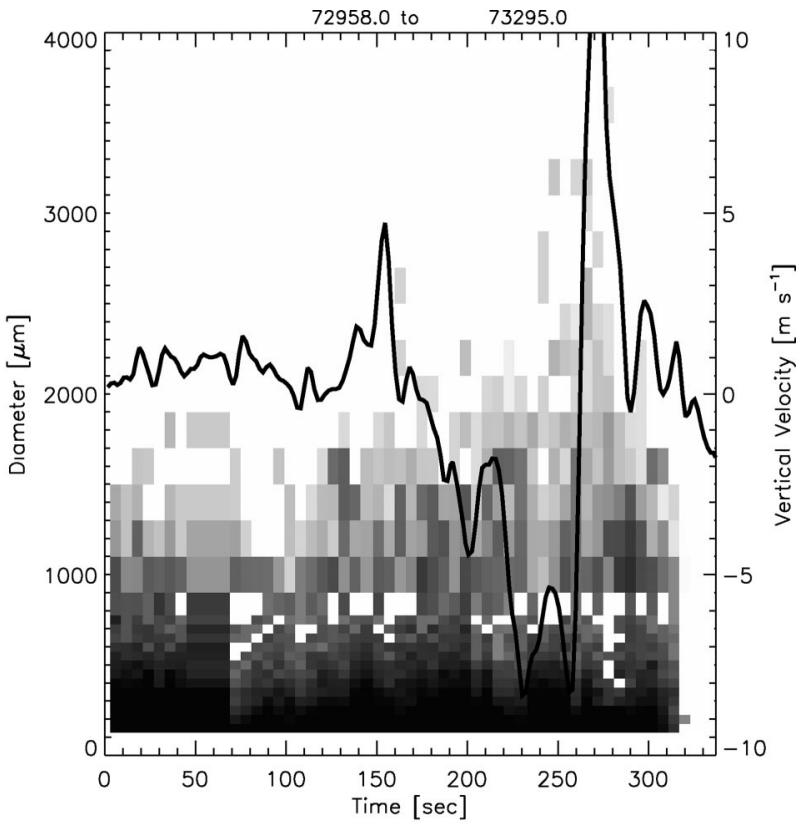

Number concentration $\left[1^{-1} \mathrm{~mm}^{-1}\right] \quad \begin{array}{rrrrr}-2 & -1 & 0 & 0 & 1\end{array}{ }^{2}$

FIG. 10. As in Fig. 8, except for time period between 2015:58 and 2021:35 UTC on 22 Sep 1987.

butions from both snow and graupel. Figure 9 shows that immediately adjacent to the convection, graupel contributes to a much higher percentage of the ice content than for locations farther into the stratiform region. As Fig. 9 is plotted on a logarithmic scale, the percentage variation is quite large, suggesting that it is unlikely that any difference in density would affect the conclusion. This may partly explain why larger sizes of hydrometeors are seen farther away from the convection in the stratiform region in Fig. 8, namely, because the snow particles tend to have larger sizes than the more dense graupel particles. Near the convection, the transport of warmer air from lower levels is clearly seen; although there are no larger particles seen, Black and Hallett (1999) showed that there was substantial liquid water in such regions as detected by the JW probe.

Figure 10 shows another example of particle size distributions measured during a penetration of Hurricane Emily, with the vertical velocity field superimposed. Here, the trends are somewhat different than those noted in Fig. 8, with greater numbers of larger hydrometeors noted near the updrafts. The major reason for these differences is the temperatures at which the penetrations were made in the convection; for time periods plotted in Fig. 10, the temperatures are just below freezing. Separation of the hydrometeors into graupel and snow (figure not shown) again showed a greater contribution of graupel near the convective regions and substantial horizontal fluctuations during the time period of the measurements. Because the flight legs were flown at

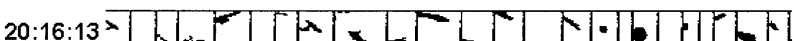

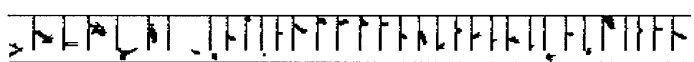

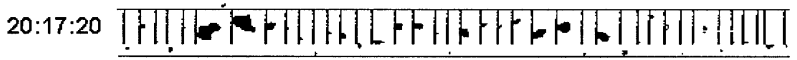

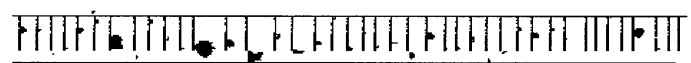

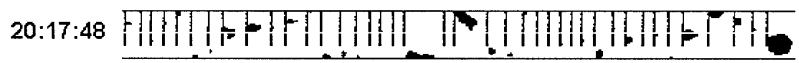

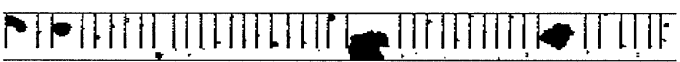

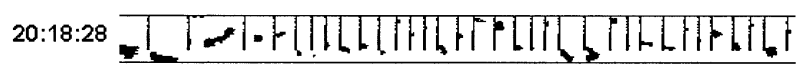

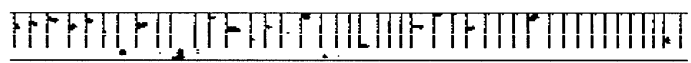

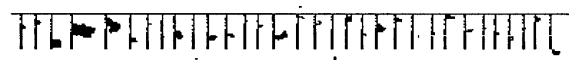

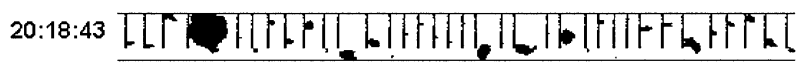

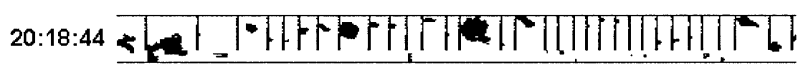

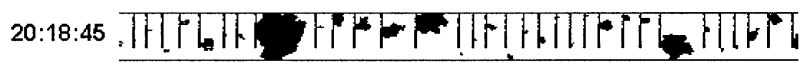

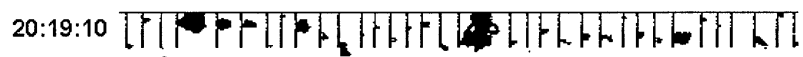

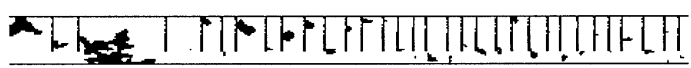

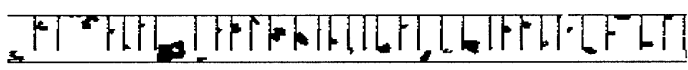

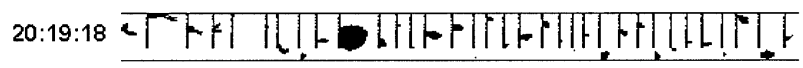

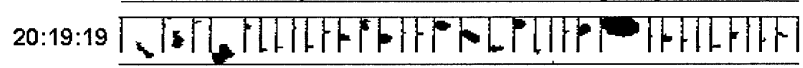

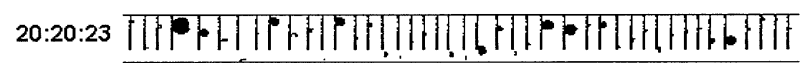

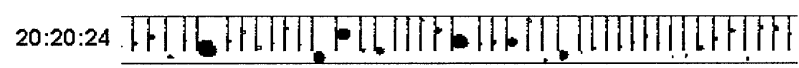
20:20:36 20:20:39

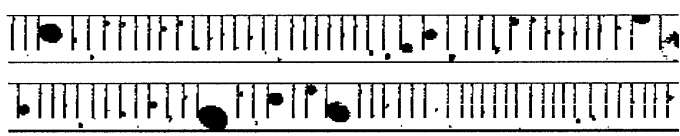

FIG. 11. Images of snow and graupel particles obtained by 2DC during time period depicted in Fig. 10. Each image bar corresponds to a height of $1600 \mu \mathrm{m}$. Substantial variations in types of particles observed during the penetration through the hurricanes are noted.

constant altitudes, this bias in the convective measurements at warmer temperatures cannot be avoided, and hence must be accounted for in subsequent analysis.

Figure 11 shows examples of hydrometeors imaged by the 2DC for the constant altitude leg depicted in Fig. 10; considerable horizontal variability in the images is noted within the leg. For measurements in stratiform regions (e.g., 2016:13 to 2017:48 UTC), small ice crystals, columns, and medium-sized graupel are observed. For updraft regions (e.g., 2018:28, 2019:10, and 2019: 19 UTC), small- to medium-sized solid hydrometeors are seen; and for downdraft regions (e.g., 2018:45, 2019: 10, and a weak downdraft at 2020:36 UTC), medium 


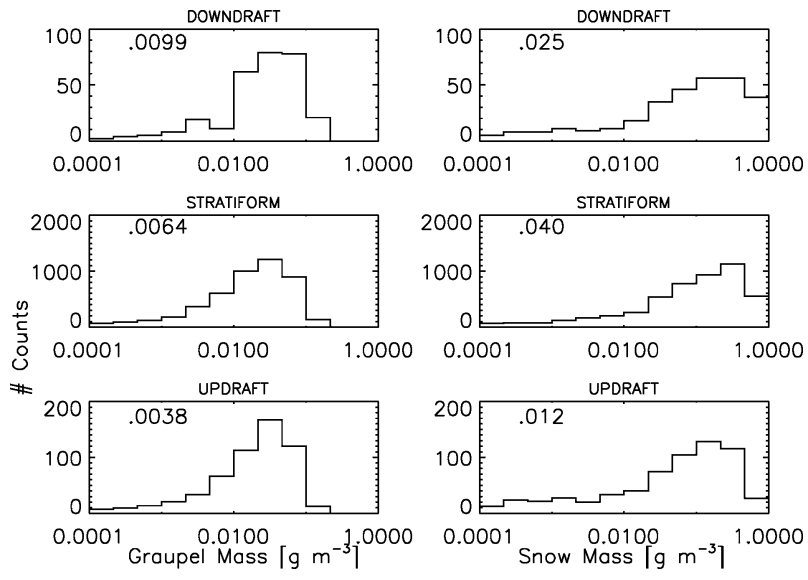

FIG. 12. Frequency distribution of graupel and snow mass content, derived from 2DC and 2DP data, sorted according to whether in updraft or downdraft core, defined following Jorgensen et al. (1985). Each count represents 6- to 10-s-averaged data. Median mass content plotted in upper-left corner of each box.

to large graupel, aggregates, and later raindrops are present. When examining all images, a lot of variability in the types of particles detected, even on short spatial scales, was detected and no simple relation could explain the types of particles observed.

A single parameterization describing the microphysical properties of a tropical cyclone might not be suitable for both the convective and stratiform regions given the differences in microphysical properties between regions. These differences are especially important now given that mesoscale models are being run with resolutions as small as $1 \mathrm{~km}$, a scale comparable to that at which microphysical observations are obtained. Bulk parameterizations describing averages over much longer flight legs are no longer appropriate. Because vertical velocity is a strong indicator of convective activity and is a prognostic variable in mesoscale models, it is hence logical to parameterize the microphysical properties depending upon whether processes are occurring in updrafts, downdrafts, or stratiform regions.

Figure 12 shows histograms of the relative frequency of occurrence of snow and graupel in the updraft, downdraft, and stratiform regions for all temperatures in Hurricanes Norbert and Emily. Graupel occurs in much higher masses in the downdraft regions, whereas snow is more common in the stratiform regions that were sampled. The relative absence of both snow and graupel in the updraft regions can be attributed to the warmer temperatures at which these observations were made; as shown by Black and Hallett (1999), liquid water would be more prevalent in these regions. Graupel would be expected to occur in higher concentrations in updrafts at colder temperatures where there would have been more time for graupel to develop. In the following section, these tropical cyclone observations are used to develop a new parameterization of mass-weighted fall speed that depends upon vertical velocity.

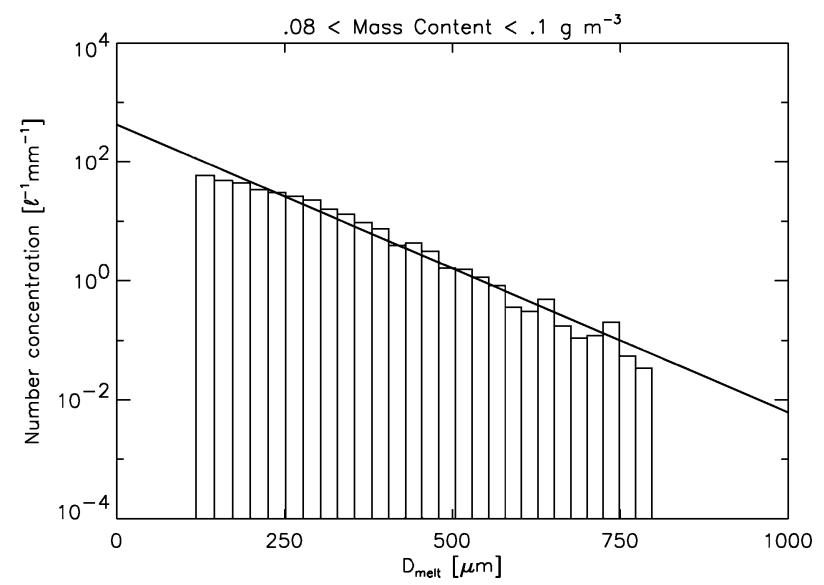

FIG. 13. Number concentration of graupel plotted as function of $D_{\text {melt }}$ for average distribution from all observations with $M_{g}$ between 0.08 and $0.1 \mathrm{~g} \mathrm{~m}^{-3}$. The solid line represents the best exponential fit to data obtained by minimizing $\chi^{2}$ between observations and fit distribution.

\section{Representation of $V_{m}$ for tropical cyclones}

In order to understand how microphysical properties affect the calculation of $V_{m}$, it is important to know how the size distributions of snow and graupel vary in both convective and stratiform regions. In this section, it is assumed that the fall speed-diameter relationship can be described by a single set of $(a, b)$ coefficients that do not vary with hydrometeor size; the uncertainties associated with this assumption have already been discussed in section 2 and are comparable in magnitude to uncertainties associated with the size distribution. In addition, the $(a, b)$ coefficients were derived from observations not associated with tropical cyclones; however, there are no such coefficients available from hurricane environments. The calculations performed here must be interpreted in the context of these uncertainties.

In order to generate fits describing the size distributions, average size distributions describing snow and graupel were first generated by stratifying the data into different mass contents and then determining an average size distribution in terms of $D_{\text {melt }}$ for each mass content range. Exponential fits to these average size distributions in terms of $D_{\text {melt }}$ were then performed. A bootstrap technique (Efron and Tibshirani 1993), a modified Monte Carlo technique whose use is appropriate when not much is known about the nature or causes of the measurement errors, was used to determine uncertainties on the fit parameters following the technique of McFarquhar et al. (2002). Figure 13 shows an example of a fit for a graupel size distribution in a stratiform region for graupel mass contents $M_{g}$ between $0.08 \mathrm{~g} \mathrm{~m}^{-3}$ and $0.1 \mathrm{~g} \mathrm{~m}^{-3}$. For each mass content range, a series of such fits were generated using average size determined from randomly drawing, with replacement, samples from the population of individual size distributions having $M_{g}$ in the appropriate range; the standard deviation of fits ob- 


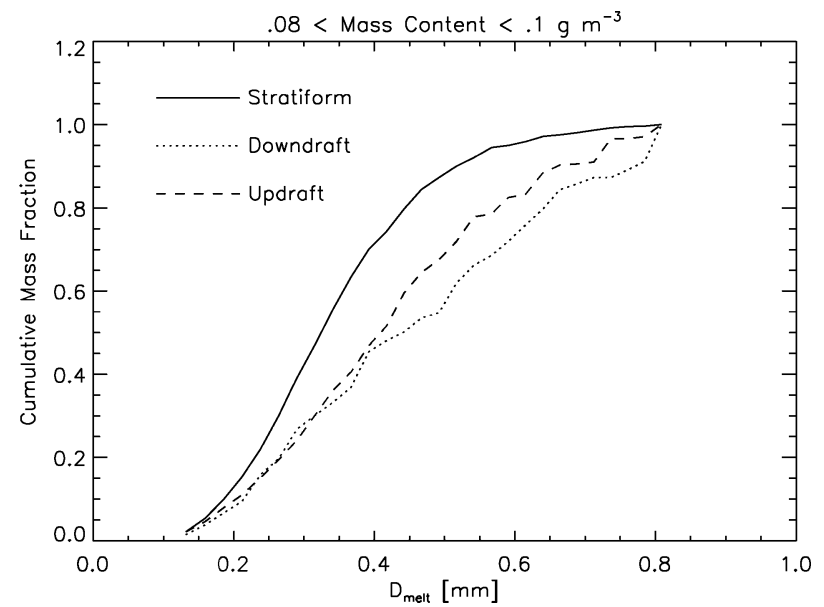

FIG. 14. Cumulative mass fraction for graupel as function of $D_{\text {melt }}$, with different line types representing size distributions measured in downdrafts, updrafts, and stratiform regions of tropical cyclones. Calculations based on average size distributions measured for $M_{g}$ between 0.08 and $0.1 \mathrm{~g} \mathrm{~m}^{-3}$.

tained for these average distributions defines the uncertainties in fit parameters. The approach of deriving fit parameters for average size distributions in different mass content ranges is similar to that used by Marshall and Palmer (1948) for generating fits to raindrop size distributions, but differs from some recent studies that fit exponential functions to individual size distributions, averaged over periods of 6 to $10 \mathrm{~s}$ (e.g., Brown and Swann 1997; Heymsfield et al. 2002). For the data presented here, the averaging approach is preferable because exponential functions did not always provide adequate fits to the individual size distributions, possibly because a statistically significant number of particles were not detected and possibly because another functional form would have provided a better fit to the data. These outliers, representing deviations from exponential behavior, would have dominated the resulting analysis.

Figure 14 further illustrates the different microphysical characteristics of the stratiform and convective regimes, justifying the need for parameterizations depending on vertical velocity. The cumulative mass fraction for graupel is plotted as a function of $D_{\text {melt }}$, with different lines representing the fractions for updrafts, downdrafts, and stratiform regions. Figure 15 performs similar analysis for cumulative snow mass fractions. Errors in $D_{\text {melt }}$ are likely about $2^{1 / 3}$ or $3^{1 / 3}$, as determined by the estimated uncertanties in particle mass. For graupel, the updraft and downdraft regions possess significantly more large particles than the stratiform regions. Examination of similar figures for other $M_{g}$ showed that this was especially true for high $M_{g}$. Note that even though the updraft observations were typically made at warmer temperatures, there is no such temperature bias in the downdraft observations, which, if anything, were made at cooler temperatures. For snow, the updraft and downdraft regions seem to possess slightly more large particles. This trend is not as clear as for the

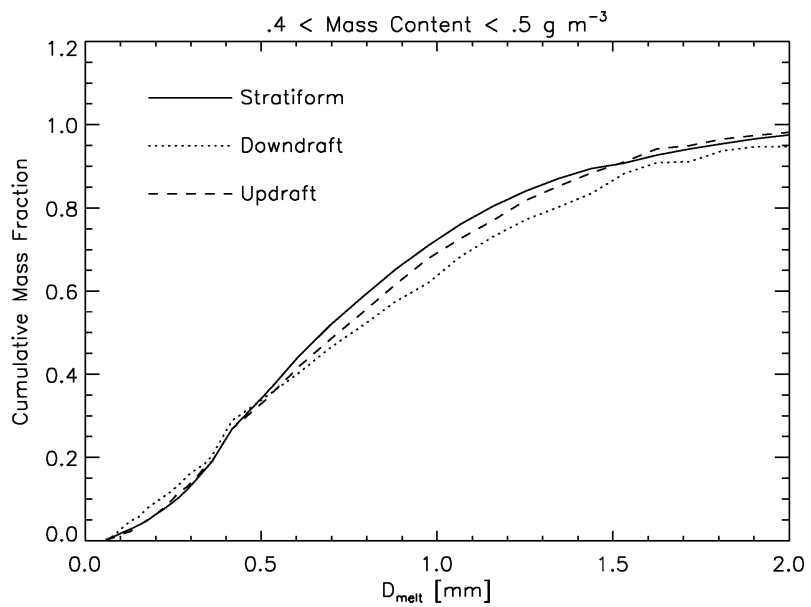

FIG. 15. As in Fig. 14, except cumulative mass contents for snow size distributions, with $M_{s}$ between 0.1 and $0.2 \mathrm{~g} \mathrm{~m}^{-3}$.

graupel mass fractions, but is most noticeable for large snow mass contents $M_{s}$.

This behavior is further illustrated when the intercept of the exponential distribution for graupel $N_{0 g}$ is plotted as a function of $M_{g}$ (Fig. 16). Uncertainty estimates for the $N_{0 g}$ data points are calculated from the bootstrap approach, and $M_{g}$ is accurate within a factor of 2 or 3 , as discussed above. Since the size distributions were parameterized in terms of $D_{\text {melt }}$, specifying both $M_{g}$ and $N_{0 g}$ is sufficient to determine the slope of the exponential distribution $\lambda_{g}$. A few trends in Fig. 16 are worth noting. First, $N_{0 g}$ for both the updraft and downdraft regions are lower than those for the stratiform regions, and this trend is statistically significant within the uncertainty estimates.

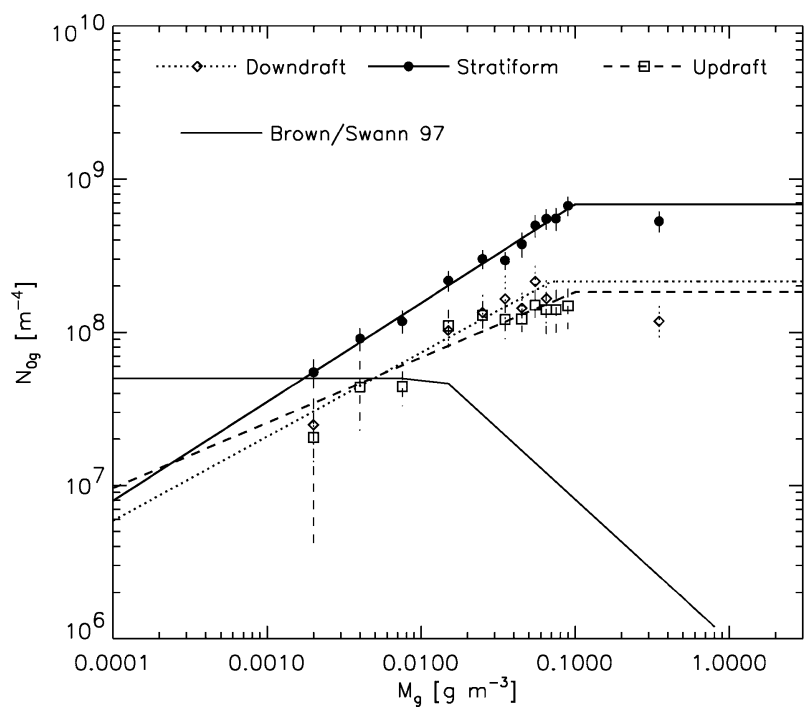

FIG. 16. Number of data points $N_{0 g}$ is a function of $M_{g}$. Different symbols and thick line types correspond to size distributions measured in updrafts, downdrafts, and stratiform regions. The thin solid lines represent the best fit to observations presented by Brown and Swann (1997). 
The uncertainties of $N_{0 g}$ for the updraft and downdraft regions are larger mainly because there are fewer data points in the sample. Note that $N_{0 g}$ is lower for updrafts and downdrafts because, given mass, the greater numbers of large crystals in these regions, corresponds to a smaller $\lambda_{g}$, which in turn forces smaller $N_{0 g}$ to force mass conservation. The solid line offers a best fit to $N_{0 g}$ as a function of $M_{g}$ for the stratiform data, as given by

$$
N_{0 g}=\left(2.6 \times 10^{9} \pm 5.0 \times 10^{8}\right) M_{g}^{(0.64 \pm 0.04)},
$$

where standard deviations of fit coefficients are calculated considering the uncertainties in the $N_{0 g}$ values. The dashed line provides a fit to the downdraft data, expressed by

$$
N_{0 g}=\left(9.0 \times 10^{8} \pm 5.3 \times 10^{8}\right) M_{g}^{(0.55 \pm 0.15)},
$$

and the dotted line provides a fit to the updraft data, given by

$$
N_{0 g}=\left(4.6 \times 10^{8} \pm 1.6 \times 10^{8}\right) M_{g}^{(0.41 \pm 0.10)} .
$$

Comparison is made with analysis of graupel size distributions recorded by Brown and Swann (1997) in weakly convective systems over southern England. There are substantial differences between the curves, especially at high $M_{g}$, and the differences are significant considering the uncertainties in the fits. There is an increase of $N_{0 g}$ with $M_{g}$ in the new parameterization, whereas there is a decrease in $N_{0 g}$ with $M_{g}$ in the Brown and Swann (1997) observations. The decrease of $N_{0 g}$ with $M_{g}$ roughly corresponds to a situation with a fixed number of graupel particles; as graupel particles grow and $M_{g}$ increases, $N_{0 g}$ must decrease in order to conserve number. The hurricane observations roughly correspond to a situation where there is not a fixed number of hydrometeors, and the total number of particles is typically larger when mass contents are greater. However, the total number increases at a slower rate than $M_{s}$; if the rate of increase were the same, the exponent of 0.64 in Eq. (14) would be 1 . This indicates that the average particle sizes are increasing with $M_{g}$.

Figure 17 describes the variation of $N_{0 s}$ as a function of $M_{s}$. There is not as clear a trend in how snow distributions vary according to updraft velocity as there is for graupel; for high and low $M_{s}$, the updraft and downdraft regions possess more large particles (smaller $N_{0 s}$ ), whereas the opposite might be true in an average sense for intermediate $M_{s}$. A best-fit line of $N_{0 s}$ to $M_{s}$ is given by

$$
N_{0 s}=1.9 \times 10^{8} \pm 2.8 \times 10^{7} M_{s}^{(0.74+0.08)} .
$$

Equation (17) is calculated from the average size distributions from both convective and stratiform regions; separate curves are not generated because differences between regions are marginal and not as significant statistically. Because snow masses are estimated using relations in terms of radar reflectivity that vary between samples, the bootstrap technique cannot be easily used to generate uncertainty estimates; instead, these esti-

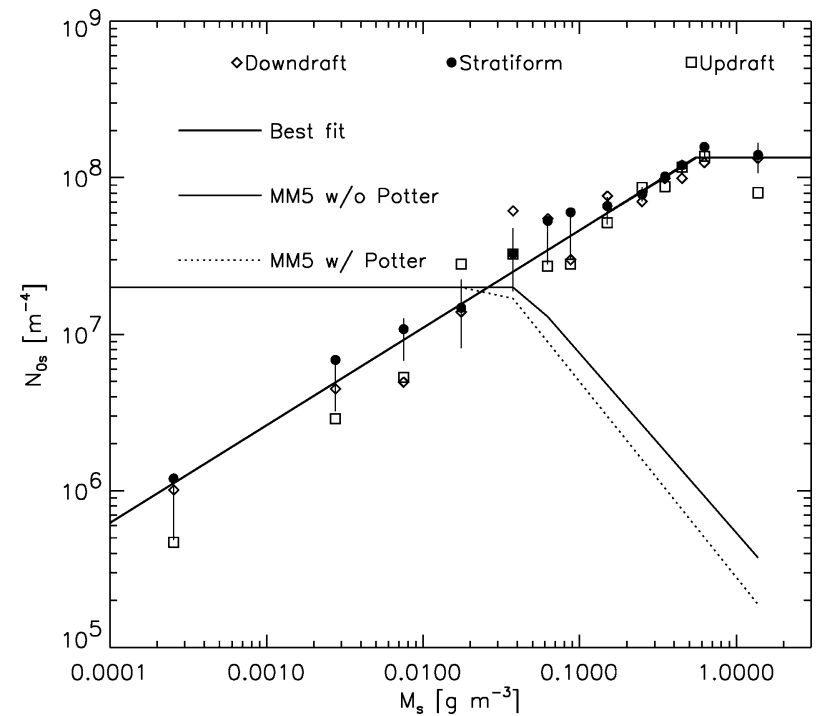

FIG. 17. As in Fig. 16, except for $N_{0 s}$ as function of $M_{s}$. The thick solid line represents the best fit to average size distributions from convective and stratiform regions. The thin solid line gives parameterization currently used in MM5 based on Sekhon and Srivastava's (1970) observations; the dashed line corrects this parameterization for inconsistencies in diameter definitions.

mates come from variations in size distributions between stratiform and convective regions.

When comparing against existing parameterizations of $N_{0 s}$ used in mesoscale models, there is a significant difference compared to the uncertainty estimates, just as noted in Fig. 16 for graupel. The parameterization shown is based on the observations of Sekhon and Srivastava (1970), and different versions that both include and do not include corrections due to difference in diameter definitions are plotted. The differences can again be attributed to different physical processes occurring in tropical cyclones than those that occur in other storm types, and parameterizations of mesoscale processes should reflect these differences. The Sekhon and Srivastava (1970) observations again correspond to a situation where total number is roughly conserved, and hence $N_{0 s}$ must decrease as the particles grow by aggregation and diffusion increasing $M_{s}$. For a snowfall rate of $5 \mathrm{~mm} \mathrm{~h}^{-1}, 8 \%$ of mass and $40 \%$ of reflectivity from Sekhon and Srivastava's (1970) observed distributions would not be detected by the $2 \mathrm{D}$ probes as it is found in particles larger than $6.4 \mathrm{~mm}$. Because $N_{0}$, and hence $\lambda$, are higher for the size distributions in tropical cyclones given the same mass content, the missing mass and reflectivity would be significantly less for the observations reported here.

Figure 18 shows the analysis in a slightly different framework. Here, $N_{0 s}$ is plotted as a function of $\lambda_{s}$, where the dots correspond to individual size distributions and the solid circles correspond to the average size distributions that were computed for different $M_{s}$. Solid lines correspond to different mass contents since a parame- 


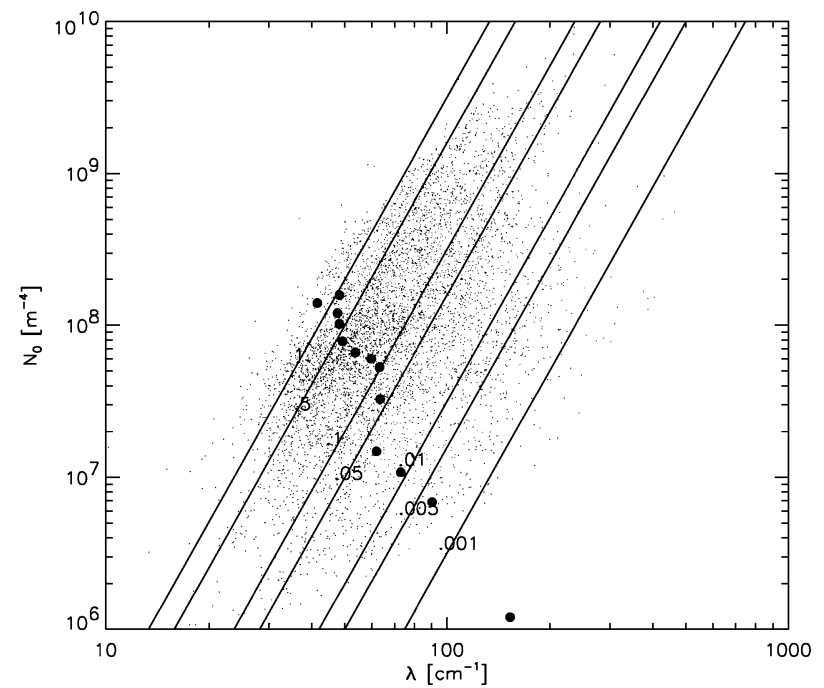

FIG. 18. Intercept $N_{0 s}$ as a function of $\lambda_{s}$, where dots correspond to fit values obtained from individual 6 - or 10 -s-averaged size distributions. Solid circles represent fits to average size distributions generated for an array of varying mass contents. Solid lines represent $N_{0 s} / \lambda_{s}$ relationships for given mass content $\left(\mathrm{g} \mathrm{m}^{-3}\right)$.

terization in terms of $D_{\text {melt }}$ ensures that there are only two independent parameters. An increase of $N_{0 s}$ with increasing $M_{s}$ is seen by comparing the positions of the solid dots with the positions of the solid lines. Note, that a direct examination of the relation between $N_{0 s}$ and $\lambda_{s}$ for the individual data points would not allow this relationship to be seen as clearly. Analysis of $N_{0 g}$ as a function of $\lambda_{g}$ showed similar trends (figure not shown).

Figure 19 compares $V_{m}$ for snow calculated using the observed tropical cyclone size distributions against both existing parameterization schemes based on Sekhon and Srivastava's (1970) observations and against those calculated using a parameterization that properly accounts for discrepancies in diameter definitions and that uses size distributions measured in tropical cyclones. The $(a, b)$ coefficients used for the calculations are from Mitchell's (1996) study for aggregates with $D_{\max }$ between 800 and $4500 \mu \mathrm{m}$, or equivalently with $D_{\text {melt }}$ between 300 and 1000 $\mu \mathrm{m}$. Figure 15 suggests that only $15 \%$ of the mass is outside of this size range. Potential variations in $(a, b)$ coefficients would also impact $V_{m}$ as discussed in section 2 .

Substantial differences are noted between the old and new parameterizations. There is a much wider variation in $V_{m}$ with mass for the midlatitude parameterizations in use by current mesoscale models than for $V_{m}$ calculated using the tropical cyclone size distributions. This occurs because of a large decrease in total number with mass as noted by the Sekhon and Srivastava (1970) observations that does not exist in the tropical cyclone data. Such differences can have substantial ramifications for the conversion rates between various microphysical species. An uncertainty estimate is not included in the plotted values of $V_{m}$ because it is difficult to ascribe a single value to this uncertainty. In reality, there are many

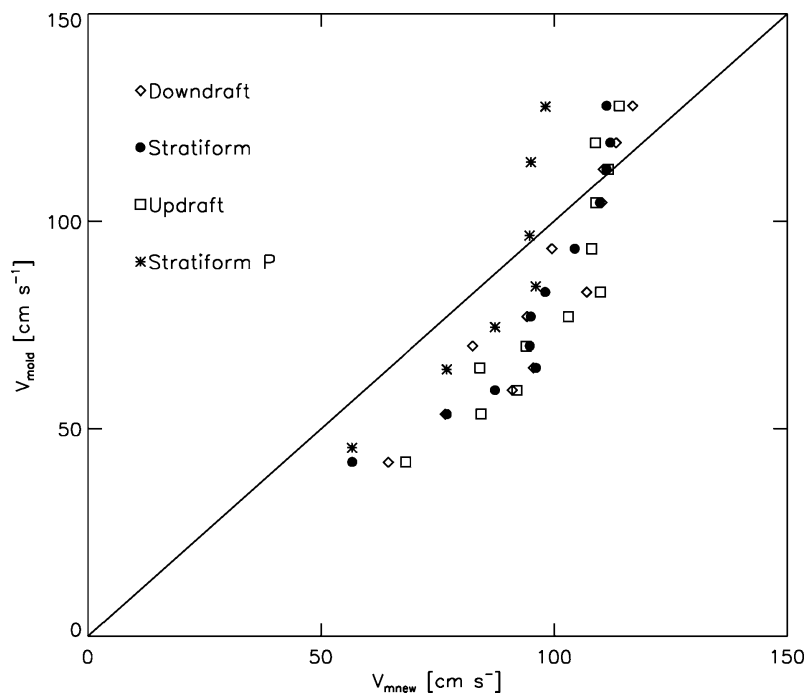

FIG. 19. Velocity $V_{m}$ for snow determined using average size distributions calculated for different mass content ranges vs $V_{m}$ for snow calculated using Reisner et al. (1998) parameterization based on Sekhon and Srivastava's (1970) observations. Different symbols represent $V_{m}$ calculated using in situ observations in updraft, downdraft, and stratiform regions of tropical cyclone. Asterisks compare $V_{m}$ calculated from in situ stratiform observations vs $V_{m}$ calculated using the Reisner et al. (1998) parameterization with corrections for inconsistent diameter definitions.

sources of uncertainty and to accurately account for them all, it is probably necessary to use an ensemble or Monte Carlo modeling approach, where random ( $a$, $b$ ) coefficients for fall speeds and distribution slopes are drawn from a population of possible values; the population drawn from may depend on the particular conditions being simulated.

Figure 20 does a similar comparison for $V_{m}$ for graupel using the tropical cyclone size distribution parameterizations and using a parameterization deduced using Brown and Swann's (1997) observations of graupel. For higher mass contents, $V_{m}$ for graupel using the new parameterization are smaller, whereas for smaller mass contents, $V_{m}$ for graupel are larger. These differences may have important ramifications for mesoscale models of tropical cyclones, all of which suffer from a problem of overprediction of graupel at high levels right now.

Finally, an analysis is performed to determine how mass density $\rho_{i}$ changes according to updraft velocity and mass content. For all times when $\rho_{i}$ was calculated following Black (1990), the data were stratified according to maximum ice water content measured by the 2DC or 2DP probe, and according to updraft velocity. Mass density $\rho_{i}$ varies from $0.13 \pm 0.15$, to $0.087 \pm 0.057$, to $0.14 \pm 0.15$ for downdrafts, stratiform regions, and updrafts, respectively, showing the prevalence of higherdensity particles in updrafts and downdrafts. Since ( $a$, $b$ ) coefficients depend on particle density, it suggests $(a, b)$ values corresponding to faster falling particles should be used for simulations of such regions. Further, 


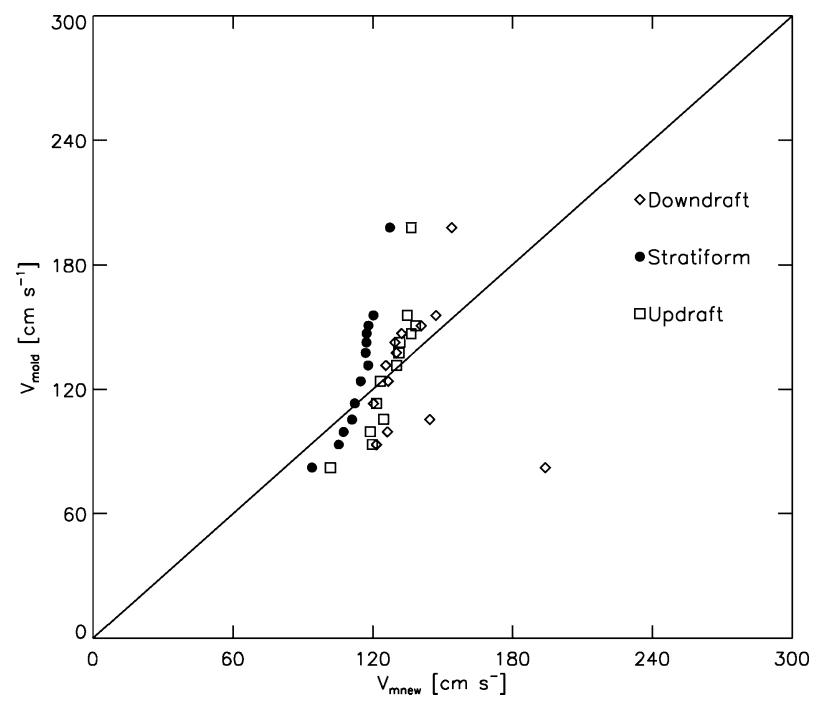

FIG. 20. As in Fig. 19, except comparison of $V_{m}$ using tropical cyclone observations of graupel vs $V_{m}$ derived using Brown and Swann's (1997) observations of graupel. Different symbols represent $V_{m}$ calculated using in situ observations in updraft, downdraft, and stratiform regions of tropical cyclone.

$\rho_{i}$ varies from $0.056 \pm 0.047$, to $0.10 \pm 0.09$, to 0.14 \pm 0.11 for ice contents less than $0.01 \mathrm{~g} \mathrm{~m}^{-3}$, between 0.01 and $0.2 \mathrm{~g} \mathrm{~m}^{-3}$, and greater than $0.2 \mathrm{~g} \mathrm{~m}^{-3}$, respectively. Since $N_{0}$ increases at a slower rate than mass content (Figs. 16 and 17), this shows that larger $\rho_{i}$ correspond to size distributions with larger mean diameters. Because of trends noted in Fig. 6, this again suggests that the use of different $(a, b)$ coefficients, corresponding to faster falling particles, might be appropriate for these regions. By examining possible $(a, b)$ values in Fig. 3, it may be possible to derive a relationship to use for simulation of a tropical cyclone, provided that information about hydrometeor density is known a priori. Hence, both the characteristics of the snow and graupel particles, as well as their size distributions, are important for accurate calculations of $V_{m}$.

\section{Summary}

The foundation of microphysical parameterizations used in current mesoscale models has been examined to show that information about the sizes, shapes, densities, and phases of frozen hydrometeors are needed for accurate prediction of mass-weighted terminal velocity $V_{m}$. Although in situ observations do not have sufficient detail to allow determination of shape effects on $V_{m}$, they can be used to provide information about the size distributions of hydrometeors in tropical cyclones. Since most current microphysical parameterization schemes were not designed for simulations of tropical cyclones, a new bulk microphysical parameterization is designed here to better represent tropical cyclone conditions. Analysis of data collected in Hurricane Norbert (1984) and in Hurricane Emily (1987) has shown that existing microphysical parameterizations are not appropriate for representing the fallout of snow and graupel in tropical cyclones. Although the specific parameterization developed here applies to tropical cyclones, the general approach of ensuring that conversion terms between hydrometeor categories are calculated using a consistent definition of diameter can be applied to any atmospheric phenomena. The principal conclusions of this study can be summarized as follows.

1) The particle diameter and particle density that are used to characterize the mass-diameter and massvelocity relationships must be defined consistently with those that are used to characterize the size distributions.

2) To calculate conversion terms between hydrometeor categories, a diameter based on equivalent projected area should be used to define the geometric sweep out of cloud water or cloud ice. Incorporation of this term into the microphysical conversions used by Lin et al. (1983) and Rutledge and Hobbs (1983, 1984) can significantly affect the transfer of mass between hydrometeor categories.

3) Differences in $(a, b)$ coefficients used to describe velocity-diameter relations of snow and graupel represent an equally important uncertainty in the calculation of $V_{m}$ as those uncertainties represented by characterizing the size distributions. Past modeling simulations have used fixed $(a, b)$ values, but these coefficients should vary with the density and mean size of snow and graupel particles.

4) In situ observations made in tropical cyclones show that the composition (i.e., graupel or snow), numbers, and sizes of particles can vary substantially depending on whether observations are collected in convective or stratiform regions.

5) The intercept and slope of exponential distributions characterizing the tropical cyclone observations have been parameterized as a function of snow and graupel mass content and vary substantially from similar parameterizations based on observations made outside tropical cyclones. In particular, the intercept of the exponential distribution was found to increase with snow or graupel mass, whereas it decreases with snow and graupel mass for current parameterizations.

6) Estimates of $V_{m}$ obtained with the tropical cyclone observations differ significantly from those obtained using parameterizations that are currently incorporated in mesoscale models.

More sophisticated two-moment microphysical schemes have recently been developed for use in numerical models. In such schemes, both the number concentration and mass concentration of different classes of hydrometeors, such as snow and graupel, are predicted (e.g., Ferrier 1994; Reisner et al. 1998). The slope and intercept of the exponential distributions are then determined from the prognostic number and mass, alleviating the need for diagnostic relations for the inter- 
cepts, as derived in this study. However, the observations acquired in the tropical cyclones and the resulting analyses are still crucial for two reasons. First, evaluation of the new schemes is sorely needed to evaluate the prognostic number especially against observations. Second, because of the computational costs in advecting more variables and parameterizing additional sources and sink terms, this two-moment option requires much more computer time and is not always used, and a simpler alternative is sometimes required. In both one- and two-moment schemes, a simple expression for massweighted terminal velocity can be obtained by using the consistent parameterization developed in this paper.

It should also be emphasized that this study was based on observations acquired in only two tropical cyclones because these data were available and because they represent some of the highest quality microphysical data obtained by NOAA in the past $20 \mathrm{yr}$. When a larger database in situ observations becomes available, the applicability of these findings, and especially the temperature dependence of these findings, should be examined. Ongoing work is concentrating on the implementation of these parameterizations in the MM5 model and in the simulation of Hurricane Erin (2001) observed during the National Aeronautics and Space Administration (NASA) Convection and Moisture Experiment (CAMEX) program. A subsequent paper will describe the sensitivity of tropical cyclones to the implementation of these new parameterizations.

Acknowledgments. This research was sponsored by the National Aeronautics and Space Administration Fourth Convection and Moisture Experiment Grant CAMEX-0000-0024. These findings do not necessarily reflect the views of the funding agency. Mike Timlin and Henian Zhang assisted in the preparation of the manuscript. Greg McFarquhar is grateful for discussions with Scott Braun that helped to focus the parameterization development aspects of the study. Bob Rauber and Mohan Ramamurthy reviewed a preliminary version of the paper. The comments of three anonymous reviewers are acknowledged.

\section{APPENDIX A}

\section{Corrected Mass Transfer Rates}

Equations that describe the transfer of mass between hydrometeor categories (cloud water, cloud ice, rain, snow, and graupel) that have been corrected for inconsistencies in diameter definitions noted in the text. Symbols are defined following the studies of Rutledge and Hobbs (1983, 1984) and Reisner et al. (1998):

$$
\begin{aligned}
\lambda_{x} & =\left(\frac{\pi \rho_{w} N_{0 x}}{\rho_{a} q_{x}}\right)^{0.25} \\
U_{x} & =\frac{a_{x} \Gamma\left(4+3 b_{x} / \beta_{x}\right)}{6 \lambda_{x}^{3 b_{x} / \beta_{x}}}\left(\frac{\pi \rho_{w}}{6 \alpha_{x}}\right)^{b_{x} / \beta_{x}}
\end{aligned}
$$

$$
\begin{aligned}
& \text { PSACI }=a_{s} \rho_{a} \gamma_{s} N_{0 s} q_{i} E_{s i}\left(\frac{\pi \rho_{w}}{6 \alpha_{s}}\right)^{\left(\sigma_{s}+b_{s}\right) / \beta_{s}} \\
& \times \frac{\Gamma\left[1+3\left(\sigma_{s}+b_{s}\right) / \beta_{s}\right]}{\lambda_{s}^{\left[1+3\left(\sigma_{s}+b_{s}\right) / \beta_{s}\right]}} \\
& \mathrm{PSACW}=a_{s} \rho_{a} \gamma_{s} N_{0 s} q_{c} E_{s c}\left(\frac{\pi \rho_{w}}{6 \alpha_{s}}\right)^{\left(\sigma_{s}+b_{s}\right) / \beta_{s}} \\
& \times \frac{\Gamma\left[1+3\left(\sigma_{s}+b_{s}\right) / \beta_{s}\right]}{\lambda_{s}^{\left[1+3\left(\sigma_{s}+b_{s}\right) / \beta_{s}\right]}} \\
& \text { PSMLT }=\frac{-2 \pi N_{0 s}}{L_{f}} K_{a}\left(T-T_{0}\right) Z_{s}^{*} B T 1 \\
& \operatorname{PSDEP}=\frac{4\left(S_{i}-1\right) N_{0 s}}{A^{\prime \prime}+B^{\prime \prime}} Z_{s}^{*} B T 1 \\
& \text { PMLTEV }=\frac{4(S-1) N_{0 s}}{A^{\prime}+B^{\prime}} Z_{s}^{*} B T 1 \\
& \text { PGACI }=a_{g} \rho_{a} \gamma_{g} N_{0 g} q_{i} E_{g i}\left(\frac{\pi \rho_{w}}{6 \alpha_{g}}\right)^{\left(\sigma_{g}+b_{g}\right) / \beta_{g}} \\
& \times \frac{\Gamma\left[1+3\left(\sigma_{g}+b_{g}\right) / \beta_{g}\right]}{\lambda_{g}^{\left[1+3\left(\sigma_{g}+b_{g}\right) / \beta_{g}\right]}} \\
& \mathrm{PGACW}=a_{g} \rho_{a} \gamma_{g} N_{0 g} q_{c} E_{g c}\left(\frac{\pi \rho_{w}}{6 \alpha_{g}}\right)^{\left(\sigma_{g}+b_{g}\right) / \beta_{g}} \\
& \times \frac{\Gamma\left[1+3\left(\sigma_{g}+b_{g}\right) / \beta_{g}\right]}{\lambda_{g}^{\left[1+3\left(\sigma_{g}+b_{g}\right) / \beta_{g}\right]}} \\
& \text { PGACR }=\pi^{2} \rho_{w} E_{g r} N_{0 g} N_{0 r}\left|U_{g}-U_{r}\right| \\
& \times\left\{\frac{5}{\lambda_{r}^{6} \lambda_{g}}+\frac{2 Z_{g} \Gamma\left[1+3 \sigma_{g} /\left(2 \beta_{g}\right)\right]}{\lambda_{r}^{5} \lambda_{g}^{\left[1+3 \sigma_{g} /\left(2 \beta_{g}\right)\right]}}\right. \\
& \left.+\frac{Z_{g}^{2} \Gamma\left[1+3 \sigma_{g} /\left(2 \beta_{g}\right)\right]}{4 \lambda_{r}^{4} \lambda_{g}^{\left[1+3 \sigma_{g} /\left(2 \beta_{g}\right)\right]}}\right\} \\
& \mathrm{PGDEP}=\frac{2 \pi\left(S_{i}-1\right) N_{0 g}}{A^{\prime \prime}+B^{\prime \prime}} Z_{g}^{*} B T 2 \\
& \text { PMLTGE }=\frac{2 \pi(S-1) N_{0 g}}{A^{\prime}+B^{\prime}} Z_{g}^{*} B T 2 \\
& \text { PRACS }=\pi^{2} \rho_{w} E_{s r} N_{0 s} N_{0 r}\left|U_{r}-U_{s}\right| \\
& \times\left(\frac{5}{\lambda_{s}^{6} \lambda_{r}}+\frac{2}{\lambda_{s}^{5} \lambda_{r}^{2}}+\frac{0.5}{\lambda_{s}^{4} \lambda_{r}^{3}}\right) \\
& \text { PSACR }=\pi^{2} \rho_{w} E_{s r} N_{0 s} N_{0 r}\left|U_{r}-U_{s}\right| \\
& \times\left(\frac{5}{\lambda_{r}^{6} \lambda_{s}}+\frac{2}{\lambda_{r}^{5} \lambda_{s}^{2}}+\frac{0.5}{\lambda_{r}^{4} \lambda_{s}^{3}}\right) \\
& Z_{s}=\left(\frac{4 \gamma_{s}}{\pi}\right)^{0.5}\left(\frac{\pi \rho_{w}}{6 \alpha_{s}}\right)^{\sigma_{s} /\left(2 \beta_{s}\right)} \\
& Z_{g}=\left(\frac{4 \gamma_{g}}{\pi}\right)^{0.5}\left(\frac{\pi \rho_{w}}{6 \alpha_{g}}\right)^{\sigma_{g} /\left(2 \beta_{g}\right)}
\end{aligned}
$$




$$
\begin{aligned}
& B T 1=\left\{0.65 \frac{\Gamma\left[1+3 \sigma_{s} /\left(2 \beta_{s}\right)\right]}{\lambda_{s}^{\left[1+3 \sigma_{s} /\left(2 \beta_{s}\right)\right]}}+0.44\left(\frac{\rho_{a} a_{s}}{\mu}\right)^{0.5}\left(\frac{\pi \rho_{w}}{6 \alpha_{s}}\right)^{\left(b_{s}+1\right) /\left(2 \beta_{s}\right)} \frac{\Gamma\left[1+3\left(\sigma_{s}+b_{s}+1\right) /\left(2 \beta_{s}\right)\right]}{\lambda_{s}^{\left[1+3\left(\sigma_{s}+b_{s}+1\right) /\left(2 \beta_{s}\right)\right]}}\right\} \\
& B T 2=\left\{0.78 \frac{\Gamma\left[1+3 \sigma_{g} /\left(2 \beta_{g}\right)\right]}{\lambda_{g}^{\left[1+3 \sigma_{g} /\left(2 \beta_{g}\right]\right.}}+0.31\left(\frac{\rho_{a} a_{g}}{\mu}\right)^{0.5}\left(\frac{\pi \rho_{w}}{6 \alpha_{g}}\right)^{\left(b_{g}+1\right) /\left(2 \beta_{g}\right)} \frac{\Gamma\left[1+3\left(\sigma_{g}+b_{g}+1\right) /\left(2 \beta_{g}\right)\right]}{\lambda_{g}^{\left[1+3\left(\sigma_{g}+b_{g}+1\right) /\left(2 \beta_{g}\right)\right]}}\right\} .
\end{aligned}
$$

\section{APPENDIX B}

\section{Original Mass Transfer Rates}

As in appendix A, except equations have not been corrected for inconsistencies between diameter definitions:

$$
\begin{aligned}
& \lambda_{x}=\left(\frac{\pi \rho_{x} N_{0 x}}{\rho_{a} q_{x}}\right)^{0.25} \\
& U_{x}=\frac{a_{x} \Gamma\left(4+b_{x}\right)}{6 \lambda_{x}^{b_{x}}} \\
& \text { PSACI }=\frac{\pi \rho_{a} a_{s} N_{0 s}}{4} q_{i} E_{s i} \frac{\Gamma\left(b_{s}+3\right)}{\lambda_{s}^{\left(b_{s}+3\right)}} \\
& \mathrm{PSACW}=\frac{\pi \rho_{a} a_{s} N_{0 s}}{4} q_{c} E_{s c} \frac{\Gamma\left(b_{s}+3\right)}{\lambda_{s}^{\left(b_{s}+3\right)}} \\
& \operatorname{PSMLT}=\frac{-2 \pi N_{0 s}}{L_{f}} K_{a}\left(T-T_{0}\right) \\
& \times\left\{\frac{0.65}{\lambda_{s}^{2}}+0.44\left(\frac{\rho_{a} a_{s}}{\mu}\right)^{0.5} \frac{\Gamma\left[\left(b_{s}+5\right) / 2\right]}{\lambda_{s}^{\left(b_{s}+5\right) / 2}}\right\} \\
& \operatorname{PSDEP}=\frac{4\left(S_{i}-1\right) N_{0 s}}{A^{\prime \prime}+B^{\prime \prime}} \\
& \times\left\{\frac{0.65}{\lambda_{s}^{2}}+0.44\left(\frac{\rho_{a} a_{s}}{\mu}\right)^{0.5} \frac{\Gamma\left[\left(b_{s}+5\right) / 2\right]}{\lambda_{s}^{\left(b_{s}+5\right) / 2}}\right\} \\
& \text { PMLTEV }=\frac{4(S-1) N_{0 s}}{A^{\prime}+B^{\prime}} \\
& \times\left\{\frac{0.65}{\lambda_{s}^{2}}+0.44\left(\frac{\rho_{a} a_{s}}{\mu}\right)^{0.5} \frac{\Gamma\left[\left(b_{s}+5\right) / 2\right]}{\lambda_{s}^{\left(b_{s}+5\right) / 2}}\right\} \\
& \mathrm{PGACI}=\frac{\pi \rho_{a} a_{g} N_{0 g}}{4} q_{i} E_{g i} \frac{\Gamma\left(b_{g}+3\right)}{\lambda_{g}^{\left(b_{g}+3\right)}} \\
& \mathrm{PGACW}=\frac{\pi \rho_{a} a_{g} N_{0 g}}{4} q_{c} E_{g c} \frac{\Gamma\left(b_{g}+3\right)}{\lambda_{g}^{\left(b_{g}+3\right)}}
\end{aligned}
$$

$$
\begin{aligned}
\text { PGACR }= & \pi^{2} \rho_{w} E_{g r} N_{0 g} N_{0 r}\left|U_{g}-U_{r}\right| \\
& \times\left(\frac{5}{\lambda_{r}^{6} \lambda_{g}}+\frac{2}{\lambda_{r}^{5} \lambda_{g}^{2}}+\frac{0.5}{\lambda_{r}^{4} \lambda_{g}^{3}}\right) \\
\text { PGDEP }= & \frac{2 \pi\left(S_{i}-1\right) N_{0 g}}{A^{\prime \prime}+B^{\prime \prime}} \quad(\mathrm{B} 10) \\
& \times\left\{\frac{0.78}{\lambda_{g}^{2}}+0.31\left(\frac{\rho_{a} a_{g}}{\mu}\right)^{0.5} \frac{\Gamma\left[\left(b_{g}+5\right) / 2\right]}{\lambda_{g}^{\left(b_{g}+5\right) / 2}}\right\} \\
\text { PMLTGE }= & \frac{2 \pi(S-1) N_{0 g}}{A^{\prime}+B^{\prime}} \\
& \times\left\{\frac{0.78}{\lambda_{g}^{2}}+0.31\left(\frac{\rho_{a} a_{g}}{\mu}\right)^{0.5} \frac{\left.\Gamma\left[b_{g}+5\right) / 2\right]}{\lambda_{g}^{\left(b_{g}+5\right) / 2}}\right\}
\end{aligned}
$$

$$
\begin{aligned}
\text { PRACS }= & \pi^{2} \rho_{s} E_{s r} N_{0 s} N_{0 r}\left|U_{r}-U_{s}\right| \\
& \times\left(\frac{5}{\lambda_{s}^{6} \lambda_{r}}+\frac{2}{\lambda_{s}^{5} \lambda_{r}^{2}}+\frac{0.5}{\lambda_{s}^{4} \lambda_{r}^{3}}\right) \\
\text { PSACR }= & \pi^{2} \rho_{w} E_{s r} N_{0 s} N_{0 r}\left|U_{r}-U_{s}\right| \\
& \times\left(\frac{5}{\lambda_{r}^{6} \lambda_{s}}+\frac{2}{\lambda_{r}^{5} \lambda_{s}^{2}}+\frac{0.5}{\lambda_{r}^{4} \lambda_{s}^{3}}\right) .
\end{aligned}
$$

\section{REFERENCES}

Black, R. A., 1990: Radar reflectivity-ice water content relationships for use above the melting layer in hurricanes. J. Appl. Meteor. 29, 955-961.

_- and J. Hallett, 1986: Observations of the distributions of ice in hurricanes. J. Atmos. Sci., 43, 802-822.

- , and J. Hallett, 1999: Electrification of the hurricane. J. Atmos. Sci., 56, 2004-2028.

— - H. B. Bluestein, and M. L. Black, 1994: Unusually strong vertical motions in a Caribbean hurricane. Mon. Wea. Rev., 122, 2722-2739.

Braham, R. R., Jr., 1990: Snow particle size spectra in lake effect snow. J. Appl. Meteor., 29, 200-207.

Braun, S. A., and R. A. Houze, 1995: Diagnosis of hydrometeor profiles from area-mean vertical velocity data. Quart. J. Roy. Meteor. Soc., 121, 23-53.

— of Hurricane Bob (1991) to planetary boundary layer parameterizations. Mon. Wea. Rev., 128, 3941-3961.

Brown, P. R. A., and P. N. Francis, 1995: Improved measurements of the ice water content in cirrus using a total-water probe. $J$. Atmos. Oceanic Technol., 12, 410-414.

, and H. A. Swann, 1997: Evaluation of key microphysical pa- 
rameters in three-dimensional cloud-model simulations using aircraft and multiparameter radar data. Quart. J. Roy. Meteor Soc., 123, 2245-2275.

Dudhia, J., 1989: Numerical study of convection observed during the winter monsoon experiment using a mesoscale two-dimensional model. J. Atmos. Sci., 46, 3077-3107.

Efron, B., and R. J. Tibshirani, 1993: An Introduction to the Bootstrap. Chapman \& Hall, 436 pp.

Ferrier, B. S., 1994: A double-moment multiple-phase four-class bulk ice scheme. Part I: Description. J. Atmos. Sci., 51, 249-280.

Gunn, K. L. S., and J. S. Marshall, 1958: The distribution with size of aggregate snow flakes. J. Meteor., 15, 452-461.

Herzegh, P. H., and P. V. Hobbs, 1985: Size spectra of ice particles in frontal clouds: Correlations between spectrum shape and cloud conditions. Ouart. J. Roy. Meteor. Soc., 111, 463-477.

Heymsfield, A. J., and J. L. Parrish, 1979: Techniques employed in the processing of particle size spectra and state parameter data obtained with the T-28 aircraft platform. NCAR Tech. Note NCAR/TN-137\&IA, National Center for Atmospheric Research, $78 \mathrm{pp}$.

- and J. Iaquinta, 2000: Cirrus crystal terminal velocities. $J$. Atmos. Sci., 57, 916-938.

_, and G. M. McFarquhar, 2002: Mid-latitude and tropical cirrus microphysical properties. Cirrus, D. K. Lynch, Ed., Oxford University Press, 78-101.

— A. Bansemer, P. R. Field, S. L. Durden, F. L. Stith, J. E. Dye, W. Hall, and C. A. Grainger, 2002: Observations and parameterizations of particle size distributions in deep tropical cirrus and stratiform precipitating clouds. Results from in situ observations in TRMM field campaigns. J. Atmos. Sci., 59, $3457-$ 3491.

Houze, R. A., Jr., 1993: Cloud Dynamics. Academic Press, 573 pp.

- P. V. Hobbs, P. H. Herzegh, and D. B. Parsons, 1979: Size distributions of precipitation particles in frontal clouds. J. Atmos. Sci., 36, 156-162.

Jorgensen, D. P., E. J. Zipser, and M. A. LeMone, 1985: Vertical motions in intense hurricanes. J. Atmos. Sci., 42, 839-856.

Khvorostyanov, V. I., and J. A. Curry, 2002: Terminal velocities of droplets and crystals: Power laws with continuous parameters over the size spectrum. J. Atmos. Sci., 59, 1872-1884.

Klein, S. A., and C. Jakob, 1999: Validation and sensitivities of frontal clouds simulated by the ECMWF model. Mon. Wea. Rev., 127, 2514-2531.

Lin, Y.-L., R. D. Farley, and H. D. Orville, 1983: Bulk parameterization of the snow field in a cloud model. J. Climate Appl. Meteor., 22, 1065-1092.

Locatelli, J. D., and P. V. Hobbs, 1974: Fall speeds and masses of solid precipitation particles. J. Geophys. Res., 79, 2185-2197.

Lord, S. J., and J. M. Lord, 1988: Vertical velocity structure in an axisymmetric, nonhydrostatic tropical cyclone model. J. Atmos. Sci., 45, 1453-1461.

-, H. E. Willoughby, and J. M. Piotrowicz, 1984: Role of a parameterized ice-phase microphysics in an axisymmetric, nonhydrostatic tropical cyclone model. J. Atmos. Sci., 41, 28362848 .

Marks, F. D., Jr., and R. A. Houze Jr., 1987: Inner core structure of Hurricane Alicia from airborne Doppler radar observations. J. Atmos. Sci., 44, 1296-1317.
Marshall, J. S., and W. M. Palmer, 1948: The distribution of raindrops with size. J. Meteor., 5, 165-166.

Matrosov, S. Y., and A. J. Heymsfield, 2000: Use of Doppler radar to assess ice cloud particle fall velocity-size relations for remote sensing and climate studies. J. Geophys. Res., 105, 22 427-22 436.

McCumber, M., W.-K. Tao, J. Simpson, R. Penc, and S.-T. Soong, 1991: Comparison of ice-phase microphysical parameterization schemes using numerical simulations of tropical convection. $J$. Appl. Meteor., 30, 985-1004.

McFarquhar, G. M., P. Yang, A. Macke, and A. J. Baran, 2002: A new parameterization of single-scattering solar radiative properties for tropical ice clouds using observed ice crystal size and shape distributions. J. Atmos. Sci., 59, 2458-2478.

Mitchell, D. L., 1996: Use of mass- and area-dimensional power laws for determining precipitation particle terminal velocities. J. Atmos. Sci., 53, 1710-1723.

Petch, J. C., G. C. Craig, and K. P. Shine, 1997: A comparison of two bulk microphysical schemes and their effects on radiative transfer using a single-column model. Quart. J. Roy. Meteor. Soc., 123, 1561-1580.

Potter, B. E., 1991: Improvements to a commonly used cloud microphysical bulk parameterization. J. Appl. Meteor., 30, 1040-1042.

Reisner, J., R. M. Rasmussen, and R. T. Bruintjes, 1998: Explicit forecasting of supercooled liquid water in winter storms using the MM5 mesoscale model. Quart. J. Roy. Meteor. Soc., 124, 1071-1107.

Rotstayn, L. D., 1997: A physically based scheme for the treatment of stratiform clouds and precipitation in large-scale models. I: Description and evaluation of microphysical processes. Quart. J. Roy. Meteor. Soc., 123, 1227-1282.

Rutledge, S. A., and P. V. Hobbs, 1983: The mesoscale and microscale structure and organization of clouds and precipitation in midlatitude cyclones. Part VIII: A model for the "seeder-feeder" process in warm-frontal rainbands. J. Atmos. Sci., 40, 1185 1206.

_ and _ - 1984: The mesoscale and microscale structure and organization of clouds and precipitation in midlatitude cyclones. Part XII: A diagnostic modeling study of precipitation development in narrow cold-frontal rainbands. J. Atmos. Sci., 41, 2949-2972.

Ryan, B. F., 2000: A bulk parameterization of the ice particle size distribution and the optical properties in ice clouds. J. Atmos. Sci., 57, 1436-1451.

Sekhon, R. S., and R. C. Srivastava, 1970: Snow spectra and radar reflectivity. J. Atmos. Sci., 27, 299-307.

Starr, D. O'C., and Coauthors 2000: Comparison of cirrus cloud models: A project of the GEWEX cloud system study (GCSS) working group on cirrus cloud systems. Preprints, 13th Int. Conf. on Clouds and Precipitation, Reno, NV, ICCP and IAMAS, 1-4.

Tao, W.-K., and J. Simpson, 1993: The Goddard Cumulus Ensemble Model. Part I: Model description. Terr. Atmos. Oceanic Sci., 4, $35-72$.

- - - and M. McCumber, 1989: An ice-water saturation adjustment. Mon. Wea. Rev., 117, 231-235.

Willoughby, H. E., H.-L. Jin, S. J. Lord, and J. M. Piotrowicz, 1984: Hurricane structure and evolution as simulated by an axisymmetric, nonhydrostatic numerical model. J. Atmos. Sci., 41, 1169-1186. 